\title{
WestVirginiaUniversity
}

THE RESEARCH REPOSITORY @ WVU

Graduate Theses, Dissertations, and Problem Reports

2012

\section{Risk Perception among Sexually Abused Female Adolescents}

Andrea M. Jones

West Virginia University

Follow this and additional works at: https://researchrepository.wvu.edu/etd

\section{Recommended Citation}

Jones, Andrea M., "Risk Perception among Sexually Abused Female Adolescents" (2012). Graduate

Theses, Dissertations, and Problem Reports. 268.

https://researchrepository.wvu.edu/etd/268

This Dissertation is protected by copyright and/or related rights. It has been brought to you by the The Research Repository @ WVU with permission from the rights-holder(s). You are free to use this Dissertation in any way that is permitted by the copyright and related rights legislation that applies to your use. For other uses you must obtain permission from the rights-holder(s) directly, unless additional rights are indicated by a Creative Commons license in the record and/ or on the work itself. This Dissertation has been accepted for inclusion in WVU Graduate Theses, Dissertations, and Problem Reports collection by an authorized administrator of The Research Repository @ WVU.

For more information, please contact researchrepository@mail.wvu.edu. 
Risk Perception among Sexually Abused Female Adolescents

Andrea M. Jones

\begin{abstract}
Dissertation submitted to The Eberly College of Arts and Sciences

at West Virginia University in partial fulfillment of the requirements

for the degree of
\end{abstract}

Doctor of Philosophy

in

Psychology

Tracy L. Morris, Ph.D., Chair

Elisa Krackow, Ph.D.

Emily L. McCave, $\mathrm{PhD}$

Aaron Metzger, Ph.D.

Claire St. Peter, Ph.D.

\author{
Department of Psychology \\ Morgantown, West Virginia \\ 2012
}

Keywords: Risk Perception, Child Sexual Abuse, Coping Styles 


\section{Abstract \\ Risk Perception among Sexually Abused Female Adolescents}

\section{Andrea M. Jones}

Previous research investigating risk recognition in female victims of child sexual abuse has focused on college-aged women and young adults to the exclusion of adolescent females, who are just entering the stage where dating and sexual relationships are becoming important. Research with college-aged women and young adults has demonstrated that women with a history of child sexual abuse are less likely to detect risk cues in social environments. Understanding how adolescents perceive risky situations is important in preventing the trajectory from child sexual abuse to later adult victimization. It also is important to understand deficits in risk perception across a developmental period to better inform programs aimed at preventing sexual revictimization. In addition, coping mechanisms have been heavily studied in adults with a history of child sexual abuse but not in adolescents with the same history. The purpose of the present study was to address the current deficit in the literature regarding child sexual abuse and perception of danger cues, as well as coping strategies used by adolescents, who are victims of child sexual abuse. Seventeen adolescent females between the ages of 14 and 16 with a sexual abuse history comprised the target sample, while twenty-four in the same age range without a sexual abuse history are included in the comparison sample. Analyses indicated that there were no differences in identified risk cues between the target and comparison sample; however, a trend was observed for individuals in the target group to leave risky social situations sooner. There was a trend for individuals with higher levels of avoidant coping to leave the scene sooner than individuals with higher levels of self-destructive coping. There also was a trend for individuals with nervous/anxious coping to leave the scene sooner than individuals with selfdestructive coping. Social anxiety was associated with longer latencies to leave dangerous settings in the target sample. Finally, abuse severity was positively associated with the number of identified risk cues, PTSD symptoms, and harm avoidance. Implications and directions for future research are discussed. 


\section{Acknowledgements}

Several people were quite influential and very helpful in brainstorming ideas, implementation, help with recruitment, and data analyses for my dissertation. First, I would like to thank Tracy Morris for all of her help with both my dissertation and guidance as my research and academic advisor during my studies at West Virginia University. Tracy truly allowed me to pursue my research interests while mentoring and helping to shape my research career. Second, I would like to thank the wonderful members of the Developmental Psychopathology Lab. Special thanks to Brian Creasy, who helped me to format vignettes for my dissertation. Your technological expertise is greatly appreciated. Thank you to Joanna Prout, who helped with reliability coding. I really appreciate the time and effort that you put forth on my project. To Jonathan Ortega, your help with recruitment is much appreciated as well as the laughs. Thank you also to Chad Brice and Chelsea Ale for your support throughout the years and with brainstorming dissertation ideas.

Also important in the formulation of my project were my committee members, Tracy Morris, Elisa Krackow, Emily McCave, Aaron Metzger, and Claire St. Peter. I appreciate your willingness to serve on my committee as well as your invaluable input.

Several supervisors were instrumental in shaping my clinical and research interests. I am especially grateful to Laura Capage for introducing me to clinical work with children and adolescents, who have been exposed to trauma, and their families. Laura truly believed in me and went the extra mile to provide training opportunities and clinical experience. Work with her at the Monongalia County Child Advocacy Center was very instrumental in helping to shape my line of research. Next, I would like to thank Terry Laurita Sigley, Tandy McClung, and Melanie Nuszkowski, whose supervision on trauma cases was phenomenal. I continue to benefit from their supervision with current clients and am sure I will benefit in the future. Finally, I would like to thank William Fremouw, who believed in my clinical skills from day one and invited me to work part time at his clinical practice for extra experience. He truly made clinical work fun.

Next, I would like to thank several friends whose support throughout my graduate studies has been incredible. Thank you to Cierra Graham, Jason Staples, Terryl Dozier, Nyakundi Michieka, Kimberly Foley, Melissa Milanak, and Jared Hershberger for all of your support and reminders to always have fun. Special thanks to Terryl Dozier for providing feedback on earlier dissertation ideas and for helping me to find relevant video vignettes for the study.

I would like to close by thanking my mother, Marcia Moore, and my grandparents Howard and Era Moore. Mom, your support and guidance is unparalleled. I could not have asked for a stronger base. I am reminded of that daily in my clinical work. Finally, I would like to dedicate my dissertation to my late grandparents, for whom education was everything. While the social climate of their youth did not allow them to pursue an education or have the same 
opportunities as I have had, they always emphasized the value of an education. My only wish is that they could have been here to see me achieve my and their dream. 


\section{Table of Contents}

Title Page

$\begin{array}{ll}\text { Abstract } & \text { ii }\end{array}$

Acknowledgements

Table of Contents $\quad$ V

List of Tables $\quad$ vii

Introduction and Literature Review 1

Mental Health Disorders and Other Outcomes Associated with CSA 1

$\begin{array}{ll}\text { Coping Styles } & 4\end{array}$

Adolescent Impulsivity and Decision Making $\quad 6$

Environmental and Behavioral Factors Associated with Revictimization 7

Assessment of Risk Recognition 11

Statement of Research Problem and Hypotheses 12

$\begin{array}{ll}\text { Method } & 13\end{array}$

$\begin{array}{ll}\text { Participants } & 13\end{array}$

$\begin{array}{ll}\text { Measures } & 14\end{array}$

$\begin{array}{ll}\text { Procedure } & 19\end{array}$

$\begin{array}{ll}\text { Results } & 20\end{array}$

Association among Abuse Severity, Risk Perception, and Latency to Leave 21

Differences in Risk Perception by Group Membership 22

Differences in Risk Perception as a Function of Coping Styles 23 
Correlations among Mental Health Symptoms and Sexual Abuse

Discussion

Examination of the Proposed Hypotheses

Implications

Study Limitations

Directions for Future Research

References

Appendices

Tables 


\section{List of Tables}

1. Psychometric Properties of Independent and Dependent Variables 74

2. Descriptive Statistics for Measures with the Total Sample 77

3. Descriptive Statistics for Measures with the Target Sample 80

4. Descriptive Statistics for Measures with the Comparison Sample 83

5. Descriptive Statistics for Vignettes with the Total Sample 86

6. Descriptive Statistics for Vignettes with the Target Sample 87

7. Descriptive Statistics for Vignettes with the Comparison Sample 88

8. Participant Demographics 89

9. Social History $\quad 93$

10. Abuse History in the Target Group 98

11. Correlations among Abuse Severity, Latency, and Identified Risk Cues in the 111 Total Sample

12. Correlations among Abuse Severity, Latency, and Identified Risk Cues in the 112 Target Sample

13. Correlations among Abuse Severity, Latency, and Identified Risk Cues in the Comparison Sample

14. Correlations between Student-Rated Social Skills and Risk Perception Using the Total Sample

15. Correlations between Parent-Rated Social Skills and Risk Perception Using the Total Sample

16. Correlations between Student-Rated Social Skills and Risk Perception Using the Target Sample

17. Correlations between Parent-Rated Social Skills and Risk Perception Using the Target Sample 
18. Correlations between Student-Rated Social Skills and Risk Perception Using the Comparison Sample

19. Correlations between Parent-Rated Social Skills and Risk Perception Using the Comparison Sample

20. Correlations among Mental Health Symptoms and Sexual Abuse

21. Correlations between Reports of Coping Styles in the Total Sample

22. Correlations between Reports of Coping Styles in the Target Sample

23. Correlations between Reports of Coping Styles in the Comparison Sample 
Risk Perception among Sexually Abused Female Adolescents

Childhood sexual abuse (CSA) has been defined in many ways ranging from broad definitions of any unwanted sexual contact to more specific definitions indicating a minimum age difference between victim and perpetrator and enumerating specific sexual acts. For the purposes of this study, CSA is classified broadly as engaging a minor in any of the following: (a) non contact sexual acts (e.g., an invitation or request to do something sexual, kissing and hugging in a sexual way, exhibition of sex organs to a minor and/or requesting a minor to exhibit their sex organs) and/or (b) contact sexual acts (e.g., fondling a minor or having the minor fondle the perpetrator in a sexual way, having a minor touch their own or the perpetrator's sex organs, attempted intercourse, and/or intercourse; see Finkelhor, 1979).

Unfortunately, CSA is a common experience affecting 21 to $32.3 \%$ of females (Briere \& Elliot, 2003; Vogeltanz, Wilsnack, Harris, Wilsnack, Wonderlich, \& Kristjanson, 1999). Of those reporting CSA, 56.2\% report being victimized by someone in their family with the most commonly reported perpetrator being a male cousin $(16.6 \%)$ followed by the victim's father (12.8\%; Vogeltanz et al.). The majority of women report their first experience of CSA as occurring between the ages of 6 and 14. Additionally, children exposed to paternal and maternal drinking, perceiving rejection by either parent, or having resided with only one biological parent by the age of 16 were at greater risk for CSA (Vogeltanz et al). Briere and Elliot (2003) found that older age, greater number of abuse incidents, multiple abusers, victimization that involved oral, anal, or vaginal penetration, and a greater level of emotional upset were associated with greater trauma symptoms.

\section{Mental Health Disorders and Other Outcomes Associated with CSA}

Victims of CSA experience a myriad of psychological outcomes including heightened prevalence of PTSD, anxiety and depression. In a meta-analysis examining the effects of CSA, 
Paolucci, Genuis and Violato (2001) concluded having experienced CSA results in a 143\% increased risk of developing PTSD symptoms and a 150\% increased risk for becoming depressed or suicidal compared to the general population. A later study found that as early as one year following CSA, victims had a higher incidence of anxiety-depression symptoms, attention problems, aggressive behavior, social problems, somatic problems, social withdrawal, externalizing behavior, internalizing behavior, and total problem score, as assessed by the Child Behavior Checklist, when compared to a normative sample (Ozbaran, Erermis, Bukusoglu, Bildik, Tamar, Ercan et al., 2009). A meta-analysis by Kendall-Tackett, Williams, and Finkelhor (1993) found similar results.

Because changes in social and romantic interests often occur as sexually abused females enter adolescence, it is important to evaluate differences between children and adolescents. In a sample of sexually abused females ages 2-18, Goldston, Turnquist, and Knutson (1989) found that younger abuse victims (ages 2-11) experienced more sexually inappropriate behaviors, sleep disturbance, depressed mood and delinquent behavior, whereas older abuse victims (ages 12-18) ran away from home more, had a higher incidence of drug use, and were engaged in sexually inappropriate behaviors. In addition, the type of sexually inappropriate behaviors differed by age with younger abuse victims engaging in more inappropriate sexual behaviors including surreptitious masturbation, public masturbation, sexual precocity, sexual experimentation/sexual initiation with younger peers, and seductive behaviors toward men. Older abuse victims were involved in more sexual precocity and seductive behaviors toward men. Adolescent victims of CSA also had less future time perspective, engaged in fewer sexual self-care behaviors, and had less social support than individuals who had not experienced CSA (Johnson, Rew \& Sternglanz, 2006). These behaviors put victims of CSA at risk for revictimization (Andrews, Corry, Slade, 
Issakids, \& Swanson, 2004; Fargo, 2009; Humphrey \& White, 2000). In addition to engaging in fewer risky sexual behaviors, non-CSA victims reported having more sexual health resources (Johnson et al., 2006) than individuals with a history of child sexual abuse.

Chronicity and timing of child sexual abuse has been shown to influence symptom presentation as well. When chronicity of maltreatment was examined versus transitory maltreatment, children who had been chronically abused had a higher incidence of anxiety and depression, as well as increased social and withdrawal problems. Regarding the timing of child sexual abuse, Trickett (1997) distinguished between middle childhood and adolescence and found distinct social and emotional characteristics for both. Studies examining victims of sexual abuse in middle childhood found children to have more inappropriate sexual activity and smaller, more unsatisfactory peer networks. Adolescents who experienced sexual abuse had more classroom behavior problems, more male peers in their social network and earlier sexual activity. Adolescents also were involved in more risky behaviors such as illegal acts and running away from home. This decreased social effectiveness has been found to be associated with elevated rates of PTSD, anxiety, and depression in CSA victims (Éthier, Lemelin \&Lacharité, 2004; Kinard, 1999; Levendosky, Okun \& Parker, 1995; Rogosch, Cicchetti, \& Aber, 1995; Trickett, 1997). Kim and Cicchetti (2004) found that social competence mediated the relation between child maltreatment and internalizing and externalizing symptoms. In contrast, there is research demonstrating that victims of CSA with high social competence, adaptive functioning skills, and positive peer relationships are more likely to have fewer internalizing and externalizing symptoms (Schultz, Tharp-Taylor, Haviland \& Jaycox, 2009).

While high levels of mental health symptoms have been found in childhood, effects of CSA extend into adulthood. For example, abused women ages 18-21 have been found to have 
increased numbers of sexual partners, unhappy pregnancies, abortions, and sexually transmitted infections when compared to women who do not have a history of child sexual abuse (van Roode, Dickson, Herbison \& Paul, 2009). They are more likely to be preoccupied with sex, be younger during their first voluntary intercourse experience, and to have been teen mothers. When investigating behaviors during intercourse, another study found that victims of CSA were three times as likely than non CSA victims to endorse the following: having had unprotected sex with their last partner, sex with individuals known only for a day, and sexually transmitted infections (Olley, 2008). The relation between CSA and lack of condom use during the last vaginal intercourse was significant even after controlling for demographic and environmental variables such as age, family type, residing with two parents and flirtatious afterschool activity. CSA victims were two times as likely to have engaged in heavy consumption of alcohol prior to sex. Similar results were found in an earlier study by Greenberg, Hennessy, Lifshay, Kahn-Krieger, Bartelli, and Downer et al. (1999).

\section{Coping Styles}

Because of the heightened negative psychological and sexual outcomes for victims of CSA, coping styles have been heavily researched. Three coping styles are consistently discussed in the literature including avoidant, self-destructive, and constructive styles. Merrill and colleagues refer to avoidant coping styles as including avoidance of people, places, situations and behaviors that remind one of the abuse; denial; distancing; and disengagement (see Merrill, Guimond, Thomsen, \& Milner, 2003 and Merrill, Thomsen, Sinclair, Gold, \& Milner, 2001), while self-destructive coping has been conceptualized to include risk-taking behaviors and substance abuse. The last coping style, constructive coping, includes expressing one's feelings, engaging in cognitive reframing, and seeking social support. Whereas Merrill and colleagues 
conceptualized all of these behaviors as constructive, others have further broken down constructive coping styles into expressive styles (e.g., talking with others about one's feelings), and cognitive styles (e.g., cognitive reframing and talking to a therapist or counselor; Burt \& Katz, 1987; Littleton, Horsley, John, \& Nelson, 2007). Burt and Katz also postulated a negative/anxious coping style; however, others have conceptualized self-destructive and avoidant coping as a means to control negative/anxious emotions.

Both avoidant and self-destructive coping styles have been associated with negative psychological and health outcomes (see Merrill et al., 2001 for a review). Fortier, DiLillo, Messman-Moore, Peugh, DeNardi and Gaffey (2009) and Littleton, Horsley, John, and Nelson (2007) concluded that avoidant coping styles are specifically related to maintenance of trauma symptoms, which are in turn related to higher levels of revictimization. Type of coping strategy used has proven to be important, as research has found that self-destructive and avoidant coping strategies partially mediate the relation between abuse severity and later functioning (Merrill et al., 2001). These findings held even after controlling for parental support, frequently postulated to be a buffer for experiencing symptoms related to the trauma. Other research has shown coping strategies to be a mediator in the relation between CSA and number of sexual partners (Merrill et al., 2003).

Different trajectories toward revictimization and sexual behaviors/functioning have been found to be related to the use of avoidant versus self-destructive coping styles; however, the use of one coping style does not preclude the use of the other (Merrill, Guimond, Thomsen, and Milner, 2003; Merrill, Thomsen, Sinclair, Gold, \& Milner, 2001). Merrill et al. (2003) found that the more severe the CSA, the more likely the individual was to use both coping styles. With regard to which coping style is associated with which specific types of behaviors, Merrill and 
colleagues (2003) found that avoidant coping strategies are associated more with increased incidence of sexual problems (e.g., sexual distress, sexual dissatisfaction, sexual functioning problems, and aversive sexual thoughts and feelings) and fewer sexual partners. Cloitre, Scarvalone, and Difede (1997) explain that dissociation and numbing (arguably an avoidant coping style) may lead to decreased awareness of one's environment and increased perception as easy prey by sexual predators. Decreased awareness of one's environment may therefore be associated with revictimization via sexual predators' perceptions.

Conversely, self-destructive coping was more associated with dysfunctional sexual behavior (e.g., having sex with strangers, secret sex and using sex as a mechanism to gain affection, coping mechanism, or means to gain power) and more sexual partners (Merrill et al., 2003). As past research has shown that women who engage in risky sexual behaviors are at greater risk for revictimization (e.g., Andrews, Corry, Slade, Issakids, \& Swanson, 2004; Arata, 2007; Fargo, 2009; Fergusson, Horwood, \& Lynskey, 1997), those using a self-destructive coping style more frequently may be at greater risk for revictimization. Because the use of avoidant and self-destructive coping styles are highly correlated (Merrill et al., 2003), greater understanding of coping styles may be important in predicting revictimization. Future studies should include attempts to determine if the use of a particular coping style is situation or person dependent.

\section{Adolescent Impulsivity and Decision Making}

One hypothesis for factors affecting risk for revictimization, especially during adolescence, is impulsivity and resulting poor decisions. Casey, Jones, and Somerville (2011) describe a neurobiological model of adolescence in which the limbic regions of the brain, responsible for motivation, develop at a faster rate than prefrontal regions of the brain, 
responsible for cognitive control. Because of this imbalance, adolescents have a period of increased sensitivity to motivation, reward, and impulse, but do not have the ability to appropriately weigh the consequences of their actions or impulses. This is described elsewhere as the dual systems model (see Harden \& Tucker-Drob, 2011; Steinberg, Albert, Cauffman, Banich, Graham, \& Woolard, 2008). Two kinds of impulsivity have been described—acting without thinking and sensation seekers (Khurana, Romer, Betancourt, Brodsky, Giannetta, \& Hurt, 2012). Khurana and colleagues explain that both individuals who act without thinking and sensation seekers will engage in risky sexual, drinking and drug use behaviors; however, sensation seekers have gained the ability to consider the consequences of their actions and are less prone to the negative effects of their behaviors (e.g., substance dependence). Applied to adolescents with a history of CSA, revictimization may be explained by the imbalance between the limbic and prefrontal regions of the brain leading to increased focus on reward (e.g., drug use, unsupervised social events, or attendance of social events where attendees are unknown or untrusted) without consideration of whether their decisions put them at greater risk for revictimization. Social and dating situations may be even more risky as work by Gardner and Steinberg (2005) and O'Brien Albert, Chein, \& Steinberg (2011) suggests that adolescents are more prone to impulsivity and poor decision making when with peers.

\section{Environmental and Behavioral Factors Associated with Revictimization}

Several environmental and behavioral factors have been associated with revictimization including dissociation, emotional flooding and numbing, alcohol and drug use, and risk recognition (Cloitre \& Rosenberg, 2006; see Messman-Moore \& Long, 2003 for a review). As such, models were created to explain the association between sexual revictimization and CSA. The social developmental perspective attributes risk factors associated with revictimization to a 
disruption in the development of affect regulation and interpersonal relatedness. This disruption is likely caused by mental health problems associated with CSA including oppositional behaviors, sexualized behaviors, anxiety, and depression—all of which are related to low social effectiveness and withdrawn behaviors. The social developmental perspective postulates that negative mental health outcomes are associated with decreased social effectiveness, which makes revictimization more likely (see Cloitre \& Rosenberg, 2006 for a review).

The ecological perspective is another model for understanding revictimization and is based on Bronfenbrenner's (1979) social ecological model. It states that sexual revictimization must be understood by considering four levels of analysis: one's ontogenic development and the microsystem, exosystem, and macrosystem. Ontogenic development includes one's personal history, how s/he responded to the abuse (e.g., traumatic sexualization, alcohol and drug abuse, dissociative disorders, powerlessness, and social isolation), and family environment. Ontogenic development shapes one's interaction with the remaining levels. The microsystem includes risk factors for future victimization including one's response to the abuse, how the perpetrator perceives the victim (e.g., assertive, easy target, powerless, lacking social/family support), and whether the perpetrator feels justified in his/her acts. The amount of resources one has (e.g., socioeconomic status, living conditions, dual or single parenthood, etc.) characterizes the exosystem. Finally, the macrosystem is composed of cultural beliefs that foster revictimization (see Grauerholtz, 2000, for a review).

Several studies have found that CSA increases the likelihood that one will be revictimized as an adolescent and then later as an adult (e.g., Fargo, 2009; Humphrey \& White, 2000). Fergusson, Horwood, and Lynskey (1997) found that family variables such as increased social disadvantage, family instability, impaired parent-child relationships, and parental 
adjustment difficulties were related to increased sexual vulnerability of CSA victims in adolescence. Fargo (2009) also found that the family environment (e.g., number of people living in the household; being a witness to intimate partner violence; maternal mental, emotional, drinking, and legal problems; and lack of parental care) predicted sexual revictimization.

Another explanation for the relation between CSA and adolescent and adult revictimization is the use of alcohol and substance abuse (Davis, 2000; Fargo, 2009; Gidycz, Loh, Lobo, Rich, Lynn, \& Pashdag, 2007; Merrill, Newell, Thomsen, Gold, Milner, Koss et al., 1999; Messman-Moore \& Long, 2002; Norris, Nurius, Dimeff, 1996; Randolph \& Mosack, 2006). One explanation for this relation may be decreased risk recognition while consuming alcohol. A study by Davis (2000) found that college students' ability to recognize risks in a written vignette depicting a dating scene was impaired while under the influence of alcohol. Heavy drinkers also report that they perceive themselves as being at greater risk for sexual victimization and have decreased ability to recognize risk cues while under the influence of alcohol (Gidycz et al., 2007; Norris, et al., 1996). In a later study by Fargo (2009), adolescent risk taking behavior (e.g., age of first alcohol use, illicit drug use, consensual sex, and whether the participant had run away from home before age 18) was found to mediate the relation between child and adolescent sexual victimization. In general, alcohol use and expected involvement in risky activities observed at one time is related to subsequent sexual victimization at a later observation (Combs-Lane \& Smith, 2002).

Psychological symptoms such as dissociation and numbing experienced by childhood victims of sexual abuse have been attributed to subsequent victimization. Both dissociation and numbing increase the risk of later victimization because of their interference with the perception of danger cues and awareness of one's environment (see Messman-Moore \& Long, 2003, for a 
review). When considering the microsystem of the social ecological model, symptoms of dissociation and numbing may serve to make the victim appear confused or distracted (Cloitre, Scarvalone and Difede, 1997) and thus appear to be an easy target for perpetrators. Cloitre and Rosenberg (2006) assert that these symptoms may hinder one's credibility, as they impair the victim's ability to remember details of experiences during a dissociated or numbed state. Lack of detail may make the victim less likely to seek help and/or less likely to be perceived as credible should they seek help from authorities. This could serve to make it less likely that they will receive the services needed to decrease future victimization.

Similarly, lower risk recognition and selection of risky environments has been attributed to revictimization. Nurius (2000) reviewed the literature on risk perception in acquaintance sexual aggression and identified several factors related to decreased risk recognition. Nurius cited alcohol consumption as being a factor limiting risk recognition, whereby the effects of alcohol serve to reduce one's ability to perceive social and risk cues. Alcohol also may serve to increase permissive behaviors and acceptance of sexually aggressive male behavior and decrease problem solving behavior. Social factors such as where one goes for entertainment may serve to decrease the probability that victims will be able to detect risk cues. In studies comparing risk recognition response latencies, women who were the victim of sexual assault or rape had longer response latencies when asked to identify risk cues and also had poorer risk recognition (Marx, Calhoun, Wilson, \& Myerson, 2001; Soler-Baillo, Marx, \& Sloan, 2005; Yeater \& O’Donohue, 2002). Furthermore, multiple-incident victims take longer to identify risk cues than women with only a single incident of victimization (Wilson, Calhoun \& Bernat, 1999).

While Nurius (2000) described most women as having an optimistic bias, believing that they are less likely than others to be the victim of sexual assault, victims of sexual assault view 
themselves as being more vulnerable to future instances of sexual victimization. Bryant (2001) found that a history of child or adolescent sexual abuse predicted greater feelings of vulnerability regarding future sexual assault and lower self-efficacy regarding how to conduct oneself in a risky situation. In a study examining women who had been assaulted after age 17, Brown, Messman-Moore, Miller and Stasser (2005) found that women who had experienced more severe instances of victimization were even more likely to see themselves as being vulnerable to future victimization. While there is a large body of literature assessing risk recognition and perceived vulnerability in college-aged child and adolescent victims of sexual abuse (e.g., Bryant, 2001; Marx, Calhoun, Wilson, \& Myerson, 2001; Soler-Baillo, Marx, \& Sloan, 2005), little work has been conducted evaluating risk recognition and perceived vulnerability while the victim is still in childhood/adolescence.

\section{Assessment of Risk Recognition}

The relation between sexual victimization status and risk perception has been evaluated by use of written, audiotape, and video vignettes. Studies examining risk perception typically have the participant watch, listen to, or read a short vignette and then indicate at what point they would leave the situation or are uncomfortable (see Soler-Baillo, Marx, \& Sloan, 2004 and Marx, Calhoun, Wilson \& Meyerson, 2001). Findings regarding latency to detect or respond to risks, however, have varied based on methodology (see Gidycz, McNamara, \& Edwards, 2006 for a review). Sleed, Durheim, Kriel, Solomon, and Baxter (2006) discussed problems associated with each type of vignette. Written vignettes are problematic as they may not be as realistic as videotaped vignettes that provide a richer context including visual depictions of actor's movements and behaviors and environmental surroundings. Furthermore, written vignettes are much more abstract in that the reader imposes his/her stereotypes onto the described character 
and "fills in the details" left out by the written description. Each participant's individual perception of the scene depicted in written vignettes may lead to differences in risk recognition not controlled for by the study. Subjective experiences of the actors also can be depicted in video vignettes more easily than in written vignettes. Finally, video vignettes allow the participant to choose where to direct their attention given a myriad of contextual information presented concurrently; whereas, the researcher directs the participant's attention more with written descriptions.

\section{Statement of Research Problem and Hypotheses}

Past work examining risk recognition in female victims of CSA largely has focused on college-aged women (e.g., Marx, Calhoun, Wilson, \& Myerson, 2001; Soler-Baillo, Marx, \& Sloan, 2005; Wilson, Calhoun, \& Bernat, 1999; Yeater \& O’Donohue, 2002). No published work to this date has been done to assess risk recognition in females who are just entering the stage where dating and sexual relationships are becoming more important. The likelihood that deficits in risk recognition exist are high given the increased likelihood of mental health disorders associated with numbing, dissociation, and decreased social competence/effectiveness (e.g., Cloitre, Scarvalone \& Difede, 1997; Éthier, Lemelin \&Lacharité, 2004; Kim \& Cicchetti, 2004; Messman-Moore \& Long, 2003); therefore, it is important to understand risk perception in adolescent females. Understanding how adolescents perceive risky situations is important in preventing the trajectory from CSA to later adult victimization described in the literature (e.g., Arata, 2000; Humphrey \& White, 2000; Randolph \& Mosack, 2006). Additionally, the majority of research examining coping styles of CSA victims has largely assessed only college-aged women and older. Moreover, no published research has been done predicting risk recognition from coping styles utilized by the victim. The present study sought to address the current deficit 
in the literature regarding CSA and perception of danger cues as well as coping strategies used by adolescents who were victims of CSA.

It was hypothesized that higher levels of abuse severity would be significantly and positively correlated with latency to leave the scene and negatively associated with the number of risk cues named. Also included as a hypothesis was that individuals in the comparison group would identify more risk cues than those in the target group and have a shorter latency to leave the scene. As the literature suggests that participants with an avoidant style may be dissociating during events that serve as trauma cues, participants with an avoidant style were hypothesized to be less likely to perceive risk cues than individuals with a self-destructive style. Social skills were hypothesized to be significantly and positively associated with the total number of risk cues identified from the five vignettes and negatively associated with latency to leave the scene. As depression, anxiety, and PTSD have been associated with childhood sexual abuse in the literature, these disorders were hypothesized to be positively and significantly correlated with the experience of childhood sexual abuse and abuse severity. Social skills were hypothesized to be negatively and significantly correlated with the experience of childhood sexual abuse and abuse severity. Finally, it was expected that participants' self-reported coping style would be significantly and positively correlated with their self-reported behavioral response regarding what they would do in each of the five vignettes.

\section{Method}

\section{Participants}

Nineteen adolescent females between the ages of 14 and 16, who had been sexually abused, were recruited for the study. A comparison sample of twenty-five adolescent females between the ages of 14 and 16, who did not report having been sexually abused, also was 
recruited. As having a cognitive delay may impair one's ability to recognize risk cues, one participant, who was receiving specialized services related to decreased cognitive ability, was excluded from the target sample. Two participants (one recruited for the target sample and one recruited for the comparison sample) chose not to participate after reading the consent forms. Thus, the final sample included 17 participants in the target sample and 24 participants in the comparison sample. Participants in the target sample were recruited from therapists and guidance counselors in North and South Carolina, West Virginia, and Pennsylvania. Those in the comparison sample were informed of the study by participants in the target group, through advertisements sent to West Virginia University faculty and staff, and from advertisements sent to churches located in the Charlotte, $\mathrm{NC}$ area. The target sample was comprised of two participants from North Carolina, four from South Carolina, ten from West Virginia, and one from Pennsylvania, while the comparison sample consisted of nine participants from North Carolina, zero from South Carolina, fourteen from West Virginia, and one from Pennsylvania. Participants received $\$ 20$ for their participation.

\section{Measures}

Demographic Questionnaire. (See Appendix A): The Demographic Questionnaire is a modified version of the Demographic Information form, as described by Bryant (2001). Adolescent participants completed the Demographic Questionnaire to obtain data about participant gender, age, and ethnicity. The questionnaire assessed who participants consider to be their primary maternal and paternal figure, the length of time they lived with each of their primary caregivers, mental health concerns affecting each of their primary caregivers, and their primary caregivers' education level and occupation. Additionally, participants were asked a series of questions regarding their alcohol use and dating and sexual history. Psychometric 
properties for all subsequently described inventories are listed in Table 1 and descriptive statistics are listed in Tables 2-4.

Childhood Sexual Victimization Questionnaire (CSVQ). The CSVQ is a modified version of the Sexual Events Questionnaire (Finkelhor, 1979), as described by Bryant (2001) and is designed to gather descriptive information about sexual abuse history. The questionnaire was further modified to assess whether more than one perpetrator was involved, whether force or threats were used, and the number of times the event occurred. Using the CSVQ, participants were asked questions regarding eight different types of sexual abuse experiences including: exhibition of sexual organs by the perpetrator, requests for sexual acts, requests for exhibition of the victim's sexual organs, being fondled in a sexual way, having another person touch or stroke their sexual organs, touching or stroking the perpetrator's sexual organs at the request of the perpetrator, attempted intercourse, and intercourse. A global index of CSA severity was created, as described by Merrill, Guimond, Thomsen, and Milner (2003). The variable was created based on a point system. Participants received one point for each of the following items endorsed in an abuse event(s): penetration, force or threats, father or stepfather as the perpetrator, more than one perpetrator, and more than four incidents. Points were cumulative across each of the eight sexual abuse experiences assessed in the CSVQ. The CSVQ is included in Appendix B.

How I Deal with Things (HIDT; Burt \& Katz, 1987). The HIDT is a 29-item, selfreport, Likert-type inventory rated on a 7-point scale. The measure contains five subscales: avoidance, expressive, nervous/anxious, cognitive, and self-destructive. Avoidance, nervous/anxious, and self-destructive styles are conceptualized as poor coping strategies, while expressive (e.g., talking to others about the abuse, taking action to recover from the abuse, and allowing one's self to experience negative feelings associated with the abuse) and cognitive 
styles (e.g., seeking psychoeducation and focusing on strategies to help one get through the rape) are viewed as positive coping strategies. It was originally designed to measure the coping strategies of women who had been raped. For the purposes of this study, items were worded more broadly to reflect coping styles used in difficult situations. Based on participant response from the current study, internal consistency was moderate to high for each of the five scales ranging from .63 to .73 , with the exception of the Nervous/Anxious scale that had an internal consistency of .28 .

Child PTSD Symptom Scale (CPSS, Foa, Johnson, Feeny, \& Treadwell, 2001). The CPSS is a 24-item, Likert-type, self-report measure rated on a 4-point scale. It was adapted from the Posttraumatic Diagnostic Scale (Foa, Cashman, Jaycox, \& Perry, 1997) to assess PTSD severity and symptom level in children and adolescents ranging in age from 8 to 18 . The scale yields a severity and PTSD total score assessing for re-experiencing, avoidance, and hyperarousal symptoms. Based on participant response from the current study, internal consistency for the total scale was .90 and .79 for the severity scale.

Beck Depression Inventory Second Edition (BDI-II; Beck, Steer, Brown, 1996). The BDI-II is a 21-item, Likert-type, self-report inventory rated on a 3-point scale. It was designed to measure depressive symptoms in adults and adolescents 13 years and older. Scores ranging from 0-13 are suggestive of minimal depression, 14-19 suggestive of mild depression, 20-28 suggestive of moderate depression, and scores ranging from 29-63 are suggestive of severe depression. The first edition of the BDI was updated to be more compatible with the DSM-IV and to include increases in appetite, weight, and sleep rather than solely assessing decreases in these symptoms (Dozois, Dobson, Ahnberg, 1998). Based on participant response from the current study, internal consistency for the BDI-II was .90 . 


\section{Multidimensional Anxiety Scale for Children (MASC; March, Parker, Sullivan,}

Stallings, \& Conners, 1997; March, 1998). The MASC is a 39-item, Likert-type, self-report inventory rated on a 4-point scale. It measures a wide variety of anxiety symptoms and includes four scales: Physical Symptoms (tense/restless and somatic/autonomic), Harm Avoidance (perfectionism and anxious coping), Social Anxiety (humiliation/rejection and public performance fears), and Separation Anxiety. Also included in the scale is the Anxiety Disorders Index. Based on participant response from the current study, internal consistency for the four scales ranged from .51 to .81 . The overall internal reliability coefficient for the entire scale was high, .79.

Social Phobia and Anxiety Inventory (SPAI; Turner, Beidel, Dancu, \& Stanley, 1989; Turner, Beidel, \& Dancu, 1996). The SPAI is a 45 -multipart-item inventory designed to assess social phobia. Items are endorsed on a 7-point Likert-type scale ranging from 0 ("Never") to 6 ("Always") and are designed to assess the cognitive, somatic, and behavioral characteristics of social anxiety. Included in the inventory are two subscales: Social Phobia and Agoraphobia. The total score is calculated by subtracting the Agoraphobia subscale score from the Social Phobia subscale. Total scores of 34-59 are indicative of "possible mild Social Phobia", scores from 60-79 are indicative of "possible Social Phobia", and scores greater than 80 are indicative of "probable Social Phobia". The Agoraphobia subscale can be used to assess Panic Disorder with scores of 39 or above being indicative of possible Panic Disorder. Based on participant response, internal consistency for the Social Phobia and Agoraphobia subscales was .98 and .87, respectively.

\section{Social Skills Improvement System: Student and Parent (SSIS; Gresham \& Elliot,}

2008). The SSIS consists of student, parent and teacher rater forms and assesses social behavior 
in the following areas: communication, cooperation, assertion, responsibility, empathy, engagement, and self-control. Additionally, the scale evaluates problem behaviors including: externalizing (e.g., exhibiting verbal and physical aggression, problems managing one's temper, and arguing), bullying, hyperactivity/inattention, internalizing (e.g., feeling anxious, lonely, sad, and/or possessing low self-esteem), and problems falling on the autism spectrum (e.g., problems interacting with others, inappropriate eye contact, having difficulty with changes in routine). In addition to scales evaluating social and problem behavior, the teacher rating scale includes an academic competence scale. Only the student and parent forms were administered to study participants. The student version contains 75 items, while the parent version contains 79. Both forms use a 4-point, Likert-type scale. Based on participant response from the current study, internal consistency of the subscales to range from .78 to .91 and .69 to .87 for the parent and student rating forms respectively.

Risk Thermometer. Participants were asked to rate the level of risk they believed each scene contained from 0, "No Risk", to 10 "High Risk". (See Appendix C.) Participants also were asked what if any risks they saw in the vignette and what they would do in the situation. Answers for what they would do in the same situation were coded for the following coping techniques: avoidance, approach/expressive, nervous/anxious feeling states, cognitive, and self-destructive behaviors. (See Appendix D, for a sample coding sheet. See Tables 5-7 for descriptive information on coping styles endorsed in the vignettes.) Risk perception was assessed via the participant's latency to leave the situation. The latency variable reflects the sum of the participant's latency to leave across each of the five video vignettes. Their recognition of risk cues was assessed via their response to "What if any risk factors did you see in the vignette?" The total number of identified risks for each participant reflects the sum of the risks they 
identified across the five video vignettes. A list of risk cues contained in each video is provided in Appendix E.

\section{Procedure}

Upon referral, the adolescent's primary caregiver received consent forms and the adolescent's assent was obtained followed by the opportunity to address any questions or concerns they had about participating in the study. Once the adolescent and parent/caregiver consented/assented to participation in the research study, the adolescent completed the questionnaire measures. The primary caregiver completed the parent rating form of the SSIS. After completing the inventories, adolescent participants were asked to watch five videos ranging from 2-4 minutes including a scene depicting implied acquaintance rape, implied date rape, implied rape involving alcohol consumption, a female being pressured for sex, and a peer being pressured to drink. Each scene was selected based on the revictimization literature suggesting that childhood sexual abuse victims are less likely to detect risks while in social settings, particularly when there is alcohol involved, and are more likely to be victimized by those they know (e.g., Nurius, 2000). Research examining self-destructive coping styles, has shown that those with this particular style are more likely to consume alcohol. For a brief description of each scene, see Appendix D. Video vignettes were obtained from youtube.com. The general content of each video vignette is similar to scenes depicted on prime time television targeting adolescent viewing audiences. Participants were instructed to stop the video at the point that they felt they would be too uncomfortable to remain in the situation and to give a rating on the risk thermometer. Participants were instructed to view the rest of the scene after their response was recorded. After viewing the scene, participants were asked to write a description of what they would do to cope in the same situation and what risk cues they saw in the video. 
Reported coping styles were coded as avoidant, approach/expressive, nervous/anxious, cognitive or self-destructive. Twenty percent of the data was coded for reliability by a trained research assistant. Reliability between the research assistant and the researcher was $81.8 \%$. Completion of the study took approximately $1 \frac{1}{2}$ hours. The study procedures were approved by the West Virginia University Institutional Review Board. Copies of the caregiver consent and adolescent assent forms can be found in Appendices G and H. Caregivers were allowed to view the video vignettes prior to their daughter participating in the study and often discussed the videos, risk cues, and risk reduction strategies with the researcher and their daughter after the study was completed. While the majority of the sample was treatment seeking, following completion of the study, participants and their parents were given a list of referral sources, in case they desired to speak more with a professional about risk perception and enhancing future safety.

\section{Results}

Demographic characteristics of the 41 participants are listed in Table 8. Of the 41 participants, 56.1\% identified as Caucasian (non Hispanic), 29.3\% as African American (non Hispanic), $12.2 \%$ identified as multiracial, and $2.4 \%$ identified as other. There were no significant racial differences between the target and comparison group, $X^{2}(1, N=41)=.75, p>$ .05 . The mean age was $15.1(S D=.74)$ with no difference between groups, $X^{2}(1, N=41)=1.23$, $p>.05$. There was a significant difference in the receipt of mental health services with $64.7 \%$ of participants in the target group endorsing having seen a mental health professional versus $29.2 \%$ in the comparison group, $X^{2}(1, N=41)=5.10, p<.05$. In addition to demographic information, information about dating, sexual activity, and drug and alcohol use was collected (See Table 9). There were no statistically significant differences between the comparison and target group for the following variables: age of first consensual sexual encounter, number of consensual sexual 
partners, frequency of alcohol intake, amount of alcohol intake, or the number of times they became drunk in the past month. Information regarding the types of abuse incurred by the target group members, relation to the perpetrator, and the presence of threats and/or force is presented in Table 10. Participants in the target group had a mean severity score of $3.59(S D=4.33)$. Individuals in the comparison group gained points towards the severity variable if they indicated that they had a sexual experience with a romantic partner and gave their consent, but that their partner used force or threats or caused harm. Participants in the comparison group had a mean severity score of $.92(S D=2.70)$.

\section{Association among Abuse Severity, Identified Risk Cues, and Latency to Leave}

Correlations among abuse severity, risk perception, and latency to leave the scene were evaluated using Pearson product moment correlations (See Tables 11-13). It was hypothesized that higher levels of abuse severity would be significantly and positively correlated with latency to leave the scene and negatively associated with the number of risk cues named; however, the study results did not support these hypotheses. While the correlation between abuse severity and latency to leave the scene was not significant in the total sample, there was a significant, positive correlation between the number of risk cues named and abuse severity, $r=.47, p<.01$ and a significant, negative correlation between latency to leave and the number of risk cues named, $r=$ $-.36, p<.05$. Similar associations were found when Pearson product moment correlations were conducted for the target sample only, as there was a significant, positive correlation between abuse severity and number of risk cues identified, $r=.43, p<.05$, and a significant, negative correlation between latency to leave the scene and the number of risk cues named, $r=-.62, p<$ .01 . Finally, in the comparison group, there was a significant, positive correlation between total number of risk cues named and the severity variable, $r=.59, p<.01$. Note participants in the 
comparison group gained points towards the severity variable if they endorsed having had a sexual experience with a romantic partner in which they their consent, but their partner used force or threats or caused harm. There was no significant association between latency to leave the scene and number of risk cues identified or abuse severity for the comparison group. There were no significant differences in the magnitude of correlations observed between abuse severity and risk perception, as measured by identified risk cues and latency to leave the scene, between the target and comparison sample, the target and total sample, or the comparison and total sample.

\section{Differences in Risk Perception by Group Membership}

A univariate analysis of variance, with total number of risk cues reported as the dependent variable, was performed to assess differences in the number of risk cues named between the comparison and target group. Another univariate analysis of variance was conducted to evaluate differences between the comparison and target group in total latency to leave the scene. It was hypothesized that participants in the comparison group would identify more risk cues than those in the target group and have a shorter latency to leave the scene. There were no significant differences in the number of risk cues named between the comparison and target group, even after controlling for social skills, as assessed by the SSIS, $F(1,40)=.00, p=$ $.962, \eta_{\mathrm{p}}{ }^{2}=.00$. Contrary to the study's hypothesis, there was a trend for individuals in the target group to leave the scene sooner $(M=333.32)$ than individuals in the comparison group $(M=$ 400.08), $F(1,40)=3.06, p=.09, \eta_{\mathrm{p}}{ }^{2}=.07$. Post hoc power analyses revealed the power to detect a significant effect for group differences in latency to leave the scene was .40 and .05 for group differences in the number of identified risk cues. Of note, there were no between group 
differences in risk perception, as measured by total number of identified risk cues or latency to leave the scene, when each video vignette was evaluated independently of the others.

\section{Differences in Risk Perception as a Function of Coping Styles}

Two univariate analyses of variance (Total Latency X Coping Style and Total Risk Cues $\mathrm{X}$ Coping Style) were conducted to evaluate differences in risk perception as a factor of coping style in the total sample. One analysis of variance, with number of risk cues named as the dependent variable, was conducted to detect differences in risk cue perception by coping styles assessed by the HIDT questionnaire. Another analysis of variance, with latency to leave the scene as the dependent variable, was conducted to detect differences in risk cue perception by coping styles assessed by the HIDT questionnaire. As past research has suggested that individuals with an avoidant coping style may dissociate in social situations that serve as a trauma cue for past abuse and that individuals with a self-destructive style are more likely to engage in dysfunctional sexual behaviors (e.g., having sex with strangers, secret sex, and using sex as a mechanism to gain attention, coping mechanism, or means to gain power), it was hypothesized that individuals using more avoidant coping styles would be less likely to perceive risk cues than individuals who used more self-destructive coping styles. Specific focus was placed on these analyses. Results from the analysis of variance, revealed no significant differences in the total number of risk cues named between individuals with a self-destructive versus an avoidant coping style. A post hoc power analysis revealed the power to detect a significant effect was .06 . When a univariate analysis of variance was conducted with latency to leave the scene as the dependent variable, a trend for differences in latency to leave the scene was observed by coping style, $F(1,40)=8.57, p=.054, \eta_{\mathrm{p}}{ }^{2}=.94$, as individuals with higher levels of avoidant coping chose to leave the scene sooner $(M=368.57)$ than individuals with 
higher levels of self-destructive coping $(M=395.39)$. A post hoc power analysis revealed the power to detect a significant effect was .62. When latency to leave the scene was compared between individuals with self-destructive versus nervous/anxious coping, there was a trend for individuals with higher levels of nervous/anxious coping to leave the scene sooner $(M=386.57)$ than individuals with higher levels of self-destructive coping $(M=395.39), F(1,40)=218.35, p$

$=.053, \eta_{\mathrm{p}}{ }^{2}=1.00$. A post hoc power analysis revealed the power to detect significant effects was .66.

\section{Correlations between Social Skills and Risk Perception}

Correlations between social skills and risk perception were evaluated by Pearson correlation coefficients (See Tables 14-19). It was hypothesized that social skills would be significantly and positively associated with the total number of risk cues identified from the five vignettes and negatively associated with latency to leave the scene. No significant correlations were observed among parent- or student-rated social skills and number of risk cues named or latency to leave the scene. There was a significant correlation between identified risk cues and social anxiety, as measured by target participants' SPAI difference score, $r=-.53, p<.05$; however, the correlation for target participants SPAI difference score and latency to leave the scene was not statistically significant. No statistically significant correlations between social anxiety, as measured by the SPAI difference score, and risk cue recognition, as assessed by identified risk cues or latency to leave the scene, were observed for the comparison or total sample.

\section{Correlations among Mental Health Symptoms and Sexual Abuse}

Pearson product moment correlations were conducted to assess associations among sexual abuse, abuse severity, depression, anxiety, PTSD, and social skills in the total sample (See 
Table 20). Depression, anxiety, PTSD, and social skills deficits have been associated with childhood sexual abuse in the literature. As such, mental health problems were hypothesized to be positively and significantly correlated with the experience of childhood sexual abuse and abuse severity, while social skills were hypothesized to be negatively and significantly correlated with the experience of childhood sexual abuse. There were no significant findings between group membership and mental health problems or social skills; however, there were several significant findings between abuse severity and mental health problems. Significant associations among the following variables were observed: severity and total risk cues identified: $r=.47, p<.01$; severity and PTSD symptoms: $r=.32, p<.05$; severity and the Harm Avoidance scale of the MASC: $r=.34, p<.05$; and severity and SPAI difference score, $r=-.38, p<.01$. While there were no statistically significant correlations between individual subscales of the SSIS using parent or student ratings and group membership, there were statistically significant correlations between the social skills standard scores and subscales (both derived separately for parent and student ratings) and mental health problems. The following correlations were found using the social skills standard score derived from student ratings: social skills standard score and BDI-II, $r=-.29, p<.05$; social skills standard score and MASC Harm Avoidance, $r=.36, p<.05$; and social skills standard score and MASC Social Anxiety, $r=-.30, p<.05$. Finally, a statistically significant correlation was observed between the social skills standard score derived from parent ratings and the BDI-II, $r=-.36, p<.05$. The following correlations were found between studentrated social skills subscales and mental health problems: Communication and BDI-II, $r=-.26, p$ $<.05$; Cooperation and BDI-II, $r=-.34, p<.05$; Self-Control and BDI-II, $r=-.27, p<.05$; Responsibility and MASC Physical, $r=-.36, p<.01$; Assertion and MASC Harm Avoidance, $r$ $=.41, p<.01$; Responsibility and MASC Harm Avoidance, $r=.34, p<.05$; MASC Social 
Anxiety and Assertion, $r=-.40, p<.01$; MASC Social Anxiety and Engagement, $r=-.47, p<$ .01 ; and SPAI Difference and Engagement, $r=-.27, p<.05$. Statistically significant correlations were found between the following parent-rated social skills subscales and mental health problems: Cooperation and CPSS, $r=-.27, p<.05$; Assertion and BDI-II, $r=-.43, p<.01$; Responsibility and BDI-II, $r=-.42, p<.01$; Responsibility and SPAI Difference, $r=.29, p<$ .05 ; Responsibility and CPSS, $r=-.39, p<.01$; Empathy and CPSS, $r=-.29, p<.05$; Engagement and BDI-II, $r=-.38, p<.01$; Self-Control and BDI-II, $r=-.29, p<.05$; and SelfControl and CPSS, $r=-.29, p<.05$.

\section{Multimethod Report of Coping Styles}

Pearson product moment correlations were conducted to assess the relation between participants' self-reported coping style, as assessed by the HIDT, and their self-reported behavioral response regarding what they would do in each of the five vignettes (See Tables 2123). It was hypothesized that participants' self-reported coping style would be significantly and positively correlated with their self-reported behavioral response regarding what they would do in each of the five vignettes. This hypothesis was partially supported, as not all of the coping styles endorsed on the HIDT were significantly and positively associated with the corresponding coping styles reported in the five vignettes. In the total sample, participant report of selfdestructive coping styles on the HIDT was positively associated with their report of selfdestructive coping styles in the vignettes, $r=.41, p<.01$. There also was a statistically significant, positive correlation between self-reported expressive coping styles, as assessed by the HIDT, and approach/expressive coping styles endorsed in the vignette scenes, $r=.30, p<$ .05. In the target sample, vignette-reported self-destructive coping was associated with selfdestructive coping, as assessed by the HIDT, $r=.63, p<.01$. Finally, in the comparison sample, 
vignette- and HIDT-rated approach/expressive coping were positively and significantly correlated, $r=.38, p<.05$.

\section{Discussion}

\section{Examination of Proposed Hypotheses}

Contrary to the proposed hypotheses, higher levels of abuse severity were not significantly and positively correlated with latency to leave the scene, nor was there a statistically significant and negative relation between abuse severity and number of identified risk cues. Rather, abuse severity and number of identified risk cues were positively correlated at a statistically significant level in the total, target and comparison samples. The positive correlation between abuse severity and number of identified risk cues by target participants is contrary to the revictimization literature that suggests women with sexual abuse and assault histories are less likely to detect risk cues (e.g., Marx, Calhoun, Wilson, \& Myerson, 2001; Soler-Baillo, Marx, \& Sloan, 2005; Yeater \& O’Donohue, 2002); however, this literature does not take into account abuse severity — only history of abuse/assault. It is possible that individuals with higher abuse severity are hypervigilant to trauma reminders (Kendall-Tackett, Williams, \& Finkelhor, 1993; Ozbaran, Erermis, Bukusoglu, Bildik, Tamar, Ercan, et al., 2009; Paolucci, Genuis, \& Violato, 2001), which would could explain the statistically significant, positive correlation between abuse severity and identified risks.

Of note, some studies finding reduced risk recognition for individuals with sexual abuse and assault histories study the effect risky behaviors, such as alcohol and substance use, have on risk recognition (e.g., Davis, 2000, Gidycz, Loh, Lobo, Rich , Lynn \& Pashdag, 2007; Merrill, Newell, Thomsen, Gold, Milner, Koss et al., 1999, Messman-Moore-Long, 2002; Norris, Nurius, Dimeff, 1996; Randolph \& Mosack, 2006). Participants in this study were not administered 
alcohol before being asked to observe risk cues. While not a specific hypothesis of the current study, there were no significant correlations observed between the number of identified risk cues and self-reported frequency of alcohol use, amount typically consumed, or the amount of times participants became drunk in the last month. There also were no observed, statistically significant correlations between latency to leave the situation and self-reported frequency of alcohol use, amount typically consumed, or the amount of times participants became drunk in the last month. These negative findings suggest that these behaviors absent of social situations are not associated with decreased risk recognition. However, as research with adult victims of CSA has shown an association between alcohol use and deficits in risk recognition, it is likely that when consuming alcohol in social situations, adolescents have similar or possibly increased deficits in risk recognition due to having an underdeveloped prefrontal cortex (See Casey, Jones, and Somerville (2011) for a review.) and alcohol-induced impairment of the prefrontal cortex responsible for cognitive control and decision making.

It was hypothesized that participants in the comparison group would identify more risk cues than those in the target group and have a shorter latency to leave the scene. Based on participant response, however, there were no group differences in the number of identified risks. This is consistent with work by Messman-Moore and Long (2002) and Merrill, Newell, Thomsen, Gold, Milner, Koss, and Rosswork (1999), who found CSA was not predictive of deficits in risk recognition, rather behaviors such as alcohol use were associated with risk recognition. While there was a positive correlation between abuse severity and risk recognition, there was no main or interaction effect for abuse severity in the number of identified risks. There were, however, group differences in the length of time group members stayed in dangerous social settings. Opposed to the study's hypothesis, there was a trend for individuals in the target 
group to have a shorter latency to leave dangerous social settings than individuals in the comparison group. This is interesting in that there were no group differences in the tendency to use avoidant coping styles, as assessed by their response to the vignettes or the HIDT, or harm avoidance, as assessed by the MASC Harm Avoidance Scale; however, it is possible that participants in the target group are more hypervigilant to risk cues and thus leave sooner than individuals in the comparison group. Finally, perhaps the same rationale for no differences existing in the number of identified risk cues is true for latency to leave the scene, such that the relation between CSA and risk recognition deficits is moderated by the involvement in risky behaviors such as alcohol use. The distinction between CSA predicting deficits in risk perception and risky behaviors predicting deficits in risk perception is an important one that should be addressed in future research with adolescents.

Because of literature suggesting that individuals with a history of CSA may have a higher tendency to dissociate in situations reminding them of a sexual trauma (Cloitre \& Rosenberg, 2006; Cloitre, Scarvalone, \& Difede, 1997; and Messman-Moore \& Long, 2003), it was hypothesized that individuals with an avoidant coping style, which includes dissociation as a strategy, would be less likely to perceive risk cues than individuals with a self-destructive style, who respond to risk cues with self-harm and dysfunctional sexual behaviors (e.g., having sex with strangers, secret sex, and using sex as a mechanism to gain attention, coping, or means to gain power). While there were no differences in the number of risk cues identified between individuals with a self-destructive coping style versus those with an avoidant style, there was a trend for individuals with higher levels of avoidant coping to leave the scene sooner than those with a self-destructive style suggesting that they may still have been perceiving risk cues. Using both latency to leave the scene and identified risk cues as a proxy for risk perception, it may be 
that when in an anxiety provoking situation, individuals with an avoidant coping style tend to dissociate, which explains the negative correlation found between latency to leave the scene and identified risk cues in the target sample. However, if given the opportunity to escape the situation, individuals with an avoidant coping style may choose to leave sooner and may therefore have lower rates of revictimization than those with a self-destructive style, making avoidance in some ways adaptive. Finally, there was a trend for individuals with a selfdestructive style to stay in risky social scenes longer than individuals with a nervous/anxious style. This is interesting given Merrill, Guimond, Thomsen, and Milner's (2003) findings that individuals with a self-destructive style had more dysfunctional sexual behavior (e.g., having sex with strangers, secret sex and using sex as a mechanism to gain affection, coping mechanism, or means to gain power) and more sexual partners. It may be that the trend for individuals with selfdestructive coping styles to stay longer in the risky social settings than those with a nervous/anxious coping style is a function of dysfunctional sexual behavior. If so, this is a possible area for treatment.

Higher levels of social skills were hypothesized to be significantly and positively associated with risk cue recognition and negatively associated with latency to leave the scene. Social skills also were expected to be negatively associated with group membership corresponding with literature identifying victims of sexual assault as being more socially withdrawn and having more social problems (Ozbaran, Erermis, Bukusoglu, Bildik, Tamar, Ercan et al., 2009). Problems relating to others socially may affect the ability for individuals to understand others' motives and consequences of their own social choices. Contrary to the study's hypothesis, no significant correlations were observed among parent- or student-rated social skills and number of risk cues identified, latency to leave the scene or group membership. There was, 
however, a statistically significant, negative correlation between identified risk cues and social anxiety in the target sample, suggesting that social anxiety may affect one's ability to detect risk cues.

Depression, anxiety, PTSD, and social skills deficits all have been associated with childhood sexual abuse in the literature (Kendall-Tackett, Williams, \& Finkelhor, 1993; Ozbaran, Erermis, Bukosoglu, Bildik, Tamar, Ercan, et al., 2009; Paolucci, Genuis \& Violato, 2001). As such, depression, anxiety, and PTSD were hypothesized to be positively and significantly correlated with the experience of childhood sexual abuse. Social skills were hypothesized to be negatively and significantly correlated with the experience of childhood sexual abuse. While there were no significant findings between group membership and mental health problems, there were statistically significant findings between abuse severity and mental health problems, which speaks to the need to consider what the abuse entailed (e.g., perpetrator identity, penetration, use of force/threats) when considering the psychological sequelae of child sexual abuse. Based on study results, this appears especially important when considering PTSD and anxiety in the form of harm avoidance (related to avoidant symptoms of PTSD). There also were no statistically significant correlations between social skills and the experience of sexual abuse. As expected, there were several statistically significant, negative correlations between social skills and mental health outcomes suggesting that social skills may serve as a protective factor against the development of mental health concerns.

Finally, because the study utilized two forms of self-report measures for coping, it was hypothesized that forms of coping endorsed on the HIDT would be associated with coping behaviors in which participants stated they would engage in each of the vignettes. Statistically significant, positive associations were found for self-destructive (in the total and target samples) 
and approach/expressive coping styles (in the comparison and total samples), but not for avoidant, cognitive, or nervous/anxious coping styles. This may indicate that when considering coping styles, providing specific scenarios, as was done with the vignettes, is important, rather than globally assessing the types of coping styles in which one engages. Both types of information are important; however, when considering safety planning and prevention of revictimization, specific scenarios may be more advantageous. Interestingly, there was a positive and statistically significant association between vignette- and HIDT-rated self-destructive forms of coping in the target sample. It is possible that for children with a history of CSA, selfdestructive coping is a more global form of coping.

\section{Implications}

Individuals with a history of CSA are at an increased risk for revictimization (Fargo, 2009; Humphrey \& White, 2000). As such, it is important to understand how this high risk for revictimization can be reduced. Based on findings from the current study, there are no differences in the ability to name risk cues between individuals with a history of CSA and those who do not have a history of CSA; however, future work should examine whether there are qualitative differences in the types of risk cues identified by individuals with a history of CSA versus those without this history. Individuals in the target group also left risky social situations sooner than did individuals in the comparison group. As such, it does not appear that the experience of sexual abuse affects one's ability to perceive risk cues; however, it may be the case that social anxiety affects one's ability to perceive risk cues, as there was a negative association between social anxiety and latency to leave the scene. Increased safety planning and education for individuals with higher levels of social anxiety may be warranted to decrease the amount of 
time that individuals with social anxiety are in dangerous settings. Specific work targeting how to leave, even when anxious, should be considered.

Based on participant report it does not appear that the experience of sexual abuse is associated with alcohol use or engaging in more sexual behavior. As such, perhaps more time should be spent investigating what may impair one's ability to keep him or herself safe. Work has been done examining the use of alcohol on risk recognition and found that individuals are less likely to perceive risk cues when under the influence of alcohol (Davis, 2000; Fargo, 2009; Gidycz, Loh, Lobo, Rich, Lynn, \& Pashdag, 2007; Merrill, Newell, Thomsen, Gold, Milner, Koss et al.,1999; Messman-Moore \& Long, 2002; Norris, Nurius, Dimeff, 1996; Randolph \& Mosack, 2006). As individuals in this study do endorse alcohol use, it is likely adolescents experience deficits in risk perception when under the influence of alcohol.

Although not a study hypothesis, there was no main effect of abuse severity for number of risk cues identified or latency to leave the scene. Abuse severity was, however, associated with the detection of more risk cues and higher rates of mental health problems. Future preventative work may focus on helping individuals who have experienced CSA, but have not had multiple abuse experiences or perpetrators, penetration, or the use of threat or force, to identify situations that put them at increased risk for harm. It also would be interesting to see if rates of revictimization are lower for women with greater abuse severity (e.g., multiple instances of the same abuse, multiple abuse occurrences, penetration, perpetration by a father or stepfather, or the use of force or threat) given abuse severity was associated with higher identified risk cues.

Much debate has occurred as to how risk perception has been measured. Findings have varied based on methodology used (see Gidycz, McNamara, \& Edwards, 2006 for a review). Asking participants to name risk cues seen in the vignettes as well as when they would leave had 
important implications for this study. For example, this study made hypotheses regarding the effects of coping style on risk perception and the effect of CSA on risk perception. Answering how coping style and the experience of child sexual abuse affect risk perception varies depending on how risk perception is assessed. No differences in identified risk cues were observed across coping styles; however, there were differences across coping styles in latency to leave a dangerous social situation. No differences in the number of identified risk cues were observed between the target and the comparison group; however, members in the target group had a shorter latency to leave the scene. Differences in findings have marked effects on the conclusions that can be drawn regarding the effect CSA and coping style have on risk perception.

\section{Study Limitations}

One limitation of the study is the sample size of the target group, which affected the power to detect significant differences in risk perception by coping style and risk perception by group membership. Several trends were observed indicating that it is possible that with an increased sample size statistically significant results may be found.

The study also relies on self-report. Parent report of participant social skills adds to the study by utilizing a multiple informant approach as does having two measures of coping styles. The addition of parent and/or teacher report ratings of mental health symptoms may allow conclusions made about the relation between mental health outcomes and CSA/CSA severity to be stronger.

While there were no demographic group differences, differences did exist between the comparison and target group with regard to use of mental health services. Use of mental health services may increase one's ability to perceive risks as trauma-focused treatments often have a risk reduction component (see, for example, Trauma-Focused Cognitive Behavioral Therapy; 
Cohen, Mannarino, \& Deblinger, 2006). Other differences such as parental involvement, monitoring, and communication of risk prevention may be different between the target and comparison group. Future research in this area should work to reduce group differences by improving methods to recruit the comparison group from the target group.

\section{Directions for Future Research}

So that the risk for revictimization of individuals with a history of CSA can be reduced and better understood, it is important to understand how environmental factors such as parenting variables (e.g., parental monitoring, parental communication of risk, parent history of sexual abuse) affect risk for revictimization. It also is possible that understanding of risks and coping styles may change over the life span, such that an adolescent's ability to perceive and respond to risk cues may be different than younger children and adult's ability to perceive and respond to risk cues. One way to study developmental aspects of risk perception may be to have siblings of varying ages as well as parents participate in studies with a procedure similar to the present study's. In addition to providing cross-sectional data, researching risk perception within families may serve to provide information regarding environmental variables contributing to risk perception. Gender differences in risk perception and coping styles are also important to understand when developing prevention programs.

Outside of knowledge regarding risk perception in social gatherings, it also is important to consider risk perception in other settings. For example, future research may work to include vignettes depicting grooming behaviors by perpetrators, particularly caregivers and family members, as $56.2 \%$ of sexual abuse events are perpetrated by someone in the victim's family (Vogeltanz, Wilsnack, Harris, Wilsnack, Wonderlich, \& Kristjanson, 1999). 


\section{References}

Andrews, G., Corry, J., Slade, T., Issakids, C., \& Swanson, H. (2004). Child sexual abuse. In M. Ezzati, A.D. Lopez, A. Rodgers, C.J.L. Murray (Eds.), Comparative quantification of health risks: Global and regional burden of disease attributable to selected major risk factors. Geneva: World Health Organisation, 1851-1940.

Arata, C. M. (2000). From child victim to adult victim: A model for predicting sexual revictimization. Child Maltreatment, 5, 28-38.

Baldwin, J. S. \& Dadds, M. R. (2006). Reliability and validity of parent and child versions of the Multidimensional Anxiety Scale for Children in community samples. Journal of the American Academy of Child and Adolescent Psychiatry, 46, 252-260.

Beck, A. T., Epstein, N., \& Brown, G. (1988). An inventory for measuring clinical anxiety. Journal of Consulting and Clinical Psychology, 56, 893-897.

Beck, A. T., Steer, R. A., \& Brown, G. K. (1996). Beck Depression Inventory manual (2 ${ }^{\text {nd }}$ Edition). San Antonio. TX: Psychological Corporation.

Ben-Porath, Y. S., Hostetler, K., Butcher, J. N., \& Graham, J. R. (1989). New subscales for the MMPI-2 social introversion (SI) scale. Psychological Assessment: A Journal of Consulting and Clinical Psychology, 1, 169-174.

Briere, J., Elliot, D. (2003). Prevalence and psychological sequelae of self-reported childhood physical and sexual abuse in a general population sample of men and women. Child Abuse \& Neglect, 27, 1205-1222.

Brofenbrenner, U. (1979). The ecology of human development. Cambridge, MA: Harvard University press. 
Brown, A. L., Messman-Moore, T. L., Miller, A. G., \& Stasser, G. (2005). Sexual victimization in relation to perceptions of risk: Mediation, generalization, and temporal stability. Personality and Social Psychology Bulletin, 31, 963-976.

Bryant, N. L. (2001). Child sexual abuse and its relationship to perceived vulnerability, powerlessness, self-efficacy, and sexual assault. Dissertation Abstracts International, 61, 4973.

Burt, M. R. \& Katz, B. L. (1987). Dimensions of Recovery from Rape: focus on Growth Outcomes, Journal of Interpersonal Violence, 2, 57-81.

Casey, B. J., Jones, R. M., \& Somerville, L. H. (2011). Braking and accelerating of the adolescent brain. Journal of Research on Adolescence, 21(1), 21-33.

Clark, D.B., Turner, S.M., Beidel, D. C., Donovan, J.E., Kirisci, L., \& Jacob, R. G. (1994). Reliability and validity of the Social Phobia and Anxiety Inventory for adolescents. Psychological Assessment, 6, 135-140.

Cloitre, M. \& Rosenberg, A. (2006). Sexual revictimization: Risk factors and prevention ( $2^{\text {nd }}$ Edition). In V. M. Follette, J. I. Ruzek, \& F. R. Abueg (eds.), Cognitive-behavioral therapies for trauma (pp. 278-304). New York: Guilford.

Cloitre, M., Scarvalone, P., \& Difede, J. (1997). Posttraumatic stress disorder, self-and interpersonal dysfunction among sexually retraumatized women. Journal of Traumatic Stress, 10, 437-452.

Cohen, J. A., Mannarino, A. P., \& Deblinger, E. (2006).Treating Trauma and Traumatic Grief in Children and Adolescents. New York, NY: Guilford Press. 
Combs-Lane, A. M. \& Smith, D. W. (2002). Risk of sexual victimization in college women: The role of behavioral intentions and risk-taking behaviors. Journal of Interpersonal Violence, 17, 165-183.

Connor, J. M., Dann, I. N., \& Twentyman, C. T. (1982). A self-report measure of assertiveness in young adolescents. Journal of Clinical Psychology, 38, 101-106.

Davis, K.L.C. (2000). Women's perceptions and responses to sexual aggression: The alcohol myopia and anxiolysis-disinhibition theories. Dissertation Abstracts International, 60, 3560.

Dozois, D. J. A., Dobson, K. S., \& Ahnberg, J. L. (1998). A psychometric evaluation of the Beck Depression Inventory-II. Psychological Assessment, 10, 83-89.

Éthier, L. S., Lemelin, J., \& Lacharité, C. (2004). A longitudinal study of the effects of chronic maltreatment on children's behavioral and emotional problems. Child Abuse \& Neglect, $28,1265-1278$.

Fargo, J. D. (2009). Pathways to adult sexual victimization: Direct and indirect behavioral risk factors across the lifespan. Journal of Interpersonal Violence, 24, 1771-1791.

Fergusson, D. M., Horwood, L. J., \& Lynskey, M. T. (1997). Childhood sexual abuse, adolescent sexual behaviors and sexual revictimization. Child Abuse \& Neglect, 21, 789-803.

Finkelhor, D. (1979). Sexually Victimized Children. New York: Free Press.

Foa, E. B., Cashman, L., Jaycox, L., \& Perry, K. (1997). The validation of a self-report measure of Posttraumatic Stress Disorder: The Posttraumatic Diagnostic Scale, Psychological Assessment, 9, 445-451. 
Foa, E. B., Johnson, K. M., Feeny, N. C., \& Treadwell, K. R. H. (2001). The Child PTSD Symptom Scale: A preliminary examination of its psychometric properties, Journal of Clinical Child Psychology, 30, 376-384.

Fortier, M. A., DiLillo, D., Messman-Moore, T. L., Peugh, J., DeNardi, K. A., \& Gaffey, K. J. (2009). Severity of child sexual abuse and revictimization: The mediating role of coping and trauma symptoms. Psychology of Women Quarterly, 33, 308-320.

Gardner, M., \& Steinberg, L. (2005). Peer Influence on Risk Taking, Risk Preference, and Risky Decision Making in Adolescence and Adulthood: An Experimental Study. Developmental Psychology, 41(4), 625-635.

Gidycz, C. A., Loh, C., Lobo, T., Rich, C., Lynn, S. J., \& Pashdag, J. (2007). Reciprocal relations among alcohol use, risk perception, and sexual victimization: A prospective analysis. Journal of American College Health, 56, 5-14.

Gidycz, C. A., McNamara, J. R., \& Edwards, K. M. (2006). Women's risk perception and sexual victimization: A review of the literature. Aggression and Violent Behavior, 11, 441-456.

Goldston, D. B., Turnquist, D. C., \& Knutson, J. F. (1989). Presenting problems of sexually abused girls receiving psychiatric services. Journal of Abnormal Psychology, 98, 314317.

Grauerholz, L. (2000). An ecological approach to understanding sexual revictimization: Linking personal, interpersonal, and sociocultural factors and processes. Child Maltreatment, 5, 517.

Greenberg, J., Hennessy, M., Lifshay, J., Kahn-Krieger, S., Bartelli, D., Downer, A., \& Bliss, M. (1999). Childhood sexual abuse and its relationship to high-risk behavior in women volunteering for HIV and STD prevention intervention. AIDS and Behavior, 3, 149-156. 
Gresham, F. M. \& Elliot, S. N. (2008). Social Skills Improvement System: Rating Scales Manual. Minneapolis, MN: Pearson.

Harden, K., \& Tucker-Drob, E. M. (2011). Individual differences in the development of sensation seeking and impulsivity during adolescence: Further evidence for a dual systems model. Developmental Psychology, 47(3), 739-746.

Humphrey, J. A. \& White, J. W. (2000). Women's vulnerability to sexual assault from adolescence to young adulthood. Journal of Adolescent Health, 27, 419-424.

Johnson, R. J., Rew, L., \& Sternglass, R. W. (2006). The relationship between childhood sexual abuse and sexual health practices of homeless adolescents. Adolescence, 41, 221-234.

Kendall-Tackett, K. A., Williams, L. M., \& Finkelhor, D. (1993). Impact of sexual abuse on children: A review and synthesis of recent empirical studies. Psychological Bulletin, 113, $164-180$.

Kim, J., Cicchetti, D. (2004). A longitudinal study of child maltreatment, mother-child relationship quality and maladjustment: The role of self-esteem and social competence. Journal of Abnormal Child Psychology, 32, 341-354.

Kinard, E. M. (1999). Perceived social skills and social competence in maltreated children. American Journal of Orthopsychiatry, 69, 465-481.

Khurana, A., Romer, D., Betancourt, L. M., Brodsky, N. L., Giannetta, J. M., \& Hurt, H. (2012). Early Adolescent Sexual Debut: The Mediating Role of Working Memory Ability, Sensation Seeking, and Impulsivity. Developmental Psychology.

Levendowsky, A. A., Okun, A., \& Parker, J. G. (1995). Depression and maltreatment as predictors of social competence and social problem-solving skills in school-age children. Child Abuse and Neglect, 19, 1183-1195. 
Littleton, H., Horsley, S., John, S., \& Nelson, D. V. (2007). Trauma coping strategies and psychological distress: A meta-analysis. Journal of Traumatic Stress, 20, 977-988.

March, J. S. (1998). Multidimensional Anxiety Scale for Children (MASC). Toronto: MultiHealth Systems, Inc.

March, J. S., Parker, J. D. A., Sullivan, K., Stallings, P., \& Conners, K. (1997). The Multidimensional Anxiety Scale for Children (MASC): Factor structure, reliability, and validity, Journal of the American Academy of Child and Adolescent Psychiatry, 36, 554565.

Marks, I. M., \& Matthews, A. M. (1979). Brief standard rating for phobic patients. Behavior Research and Therapy, 17, 263-267.

Marx, B. P., Calhoun, K. S., Wilson, A. E., \& Myerson, L. A. (2001). Sexual revictimization prevention: An outcome evaluation. Journal of consulting and Clinical Psychology, 69, 25-32.

Merrill, L. L., Guimond, J. M., Thomsen, C. J., \& Milner, J. S. (2003). Child Sexual Abuse and number of Sexual Partners in Young Women: The Role of Abuse Severity, Coping Style, and Sexual Functioning, Journal of Consulting and Clinical Psychology, 71, 987-996.

Merrill, L. L., Newell, C. E., Thomsen, C. J. Gold, S. R., Milner, J. S., Koss, M. P., \& Rosswork, S. G. (1999). Childhood abuse and sexual revictimization in a female Navy recruit sample. Journal of Traumatic Stress, 12, 211-225.

Merrill, L. L., Thomsen, C. J., Sinclair, B. B., Gold, S. R., \& Milner, J. S. (2001). Predicting the impact of child sexual abuse on women: The role of abuse severity, parental support, and coping strategies. Journal of Consulting and Clinical Psychology, 69, 992-1006. 
Messman-Moore, T. L., Long, P. J. (2002). Alcohol and substance use disorders as predictors of child to adult sexual revictimization in a sample of community women. Violence and Victims, 17, 319-340.

Messman-Moore, T. L. \& Long, P. J. (2003). The role of childhood sexual abuse sequelae in the sexual revictimization of women: An empirical review and theoretical reformulation. Clinical Psychology Review, 23, 537-571.

Norris, J., Nurius, P. S. \& Dimeff, L. A. (1996). Through her eyes: Factors affecting women's perception of and resistance to acquaintance sexual aggression threat. Psychology of Women Quarterly, 20, 123-145.

Nurius, P. S. (2000). Risk perception for acquaintance sexual aggression: A social cognitive perspective. Aggression and Violent Behavior, 5, 63-78.

O'Brien, L., Albert, D., Chein, J., \& Steinberg, L. (2011). Adolescents prefer more immediate rewards when in the presence of their peers. Journal of Research on Adolescence, 21(4), $747-753$.

Ollendick, T. H. (1983). Reliability and validity of the revised Fear Survey Schedule for Children (FSSC-R). Behavioral Research and Therapy, 21, 685-692.

Olley, B. O. (2008). Child sexual abuse as a risk factor for sexual risk behaviors among socially disadvantaged adolescents in Ibadan, Nigeria. Vulnerable Children and Youth Studies, 3, 243-248.

Osman, A., Williams, J. E., Espenschade, K., Gutierrez, P. M., Bailey, J. R., \& Chowdhry, O. (2009). Further evidence of the reliability and validity of the Multidimensional Anxiety Scale for Children (MASC) in psychiatric inpatient samples. Journal of Psychopathology and Behavioral Assessment, 31, 201-214. 
Ozbaran, B., Erermis, S., Bukusoglu, N., Bildik, T., Tamar, M., Ercan, E. S., Aydin, C., \& Cetin, S. K. (2009). Social and emotional outcomes of child sexual abuse: A clinical sample in Turkey. Journal of Interpersonal Violence, 24, 1478-1493.

Paolucci, E., E., Genuis, M. L., \& Violato, C. (2001). A meta-analysis of the published research on the effects of child abuse. The Journal of Psychology, 135, 17-36.

Radloff, L. S. (1977). The CES-D Scale: A self-report depression scale for research in the general population. Applied Psychological Measurement, 1, 385-401.

Randolph, M. E. \& Mosack, K. E. (2006). Factors mediating the effects of childhood sexual abuse on risky sexual behavior among college women. Journal of Psychology \& Human Sexuality, 18, 23-40.

Reynolds, C. R. \& Richmond, B. O. (1978). What I think and feel: A revised measure of children's manifest anxiety. Journal of Abnormal Child Psychology, 6, 271-280.

Rogosch, F. A., Cicchetti, D., \& Aber, J. L. (1995). The role of child maltreatment in early deviations in cognitive and affective processing abilities and later peer problems. Development and Psychopathology, 7, 591-609.

Rynn, M. A., Barber, J. P., Khalid-Khan, S., Siqueland, L., Dembiski, M., McCarthy, K. S., \& Gallop, R. (2006). The psychometric properties of the MASC in a pediatric psychiatric sample. Anxiety Disorders, 20, 139-157.

Shultz, D., Tharp-Taylor, S., Haviland, A., \& Jaycox, L. (2009). The relationship between protective factors and outcomes for children investigated for maltreatment. Child Abuse \& Neglect, 33, 684-698. 
Sleed, M., Durrheim, K., Kriel, A., Solomon, V., \& Baxter, V. (2002). The effectiveness of the vignette methodology: A comparison of written and video vignettes in eliciting response about date rape. South African Journal of Psychology, 32, 21-28.

Soler-Baillo, J. M., Marx, B. P., \& Sloan, D. M. (2005). The psychophysiological correlates of risk recognition among victims and non-victims of sexual assault. Behavior Research and Therapy, 43, 169-181.

Spielberger, C. (1973). Manual for the State-Trait Anxiety Inventory for Children, Palo Alto, CA: Consulting Psychologists Press.

Spielberger, C. D., Edwards, C. D., Montuori, J., \& Lushene, R. (1973). State-Trait Anxiety Inventory for Children. Palo Alto, CA: Consulting Psychological Press.

Steinberg, L., Albert, D., Cauffman, E., Banich, M., Graham, S., \& Woolard, J. (2008). Age differences in sensation seeking and impulsivity as indexed by behavior and self-report: Evidence for a dual systems model. Developmental Psychology, 44(6), 1764-1778.

Trickett, P. K. (1997). Sexual and physical abuse and the development of social competence. In: Luthar, S. S., Burack, J. A., Cicchetti, D., Weisz, J. R. (Eds.). Developmental psychopathology: Perspectives on adjustment, risk, and disorders. (pp. 390-416). New York, NY: Cambridge University Press.

Turner, S. M., Beidel, D. C., Dancu, C. V., \& Stanley, M. A. (1989). An empirically derived inventory to measure social fears and anxiety: The Social Phobia and Anxiety Inventory, Psychological Assessment, 1, 35-40.

Turner, S. M., Beidel, D. C., \& Dancu, C. V. (1996). Social Phobia and Anxiety Inventory. Multi-Health Systems, Inc. 
Twentyman, C., Boland, T., \& McFall, R (1981). Heterosexual avoidance in college males. Behavior Modification, 5, 523-552.

Van Roode, T., Dickson, N., Herbison, P., \& Paul, C. (2009). Child sexual abuse and persistence of risky sexual behaviors and negative sexual outcomes over adulthood: Findings from a birth cohort. Child Abuse \& Neglect, 33, 161-172.

Vogeltanz, N. D., Wilsnack, S. C., Harris, T. R., Wilsnack, R. W., Wonderlich, S. A., \& Kristjanson, A. F. (1999). Prevalence and risk factors for childhood sexual abuse in women: National survey findings. Child Abuse \& Neglect, 23, 579-592.

Watson, D., \& Friend, R. (1969). Measurement of social-evaluative anxiety. Journal of Clinical Psychology, 33, 448-457.

Wilson, A. E., Calhoun, K. S., \& Bernat, J. A. (1999). Risk recognition and trauma-related symptoms among sexually revictimized women. Journal of Consulting and Clinical Psychology, 67, 705-710.

Yeater, E. A. \& O’Donohue, W. (2002). Sexual revictimization: The relationship among knowledge, risk perception, and ability to respond to high risk situations. Journal of Interpersonal Violence, 17, 1135-1144. 


\section{Appendix A}

\section{Demographic Questionnaire}

Please check the answers that apply to you and fill in all answer spaces:

1. Age:

2. Ethnic Group:

(1) Caucasian (non Hispanic)

(5) Asian-American

(2) Caucasian (Hispanic)

(6) American Indian

(3) African American (non Hispanic)

(7) Multiracial

(4) African American (Hispanic)

(8) Other (specify)

3. Who do you consider to be your primary maternal figure?
(1) Biological mother
(3) Grandmother
(2) Stepmother
(4) Other (describe)

4. How many years did you live with your primary maternal figure between the ages of birth through the present?
(1) 0 years
(2) $1-5$ years
(3) 6-10 years
(4) 11-16 years

5. Are you aware of any type of mental health concern(s) that your primary maternal figure experienced during your childhood?
(1) No

(2) Yes

6. If yes, check all mental health concerns applicable to that person:

(1) Depression

(2) Excessive worry and anxiety

(3) Anxiety in social situations

(4) Panic Attacks
(5) Alcohol Abuse

(6) Thoughts about suicide

(7) Other (describe)

7. What is the highest level of education your primary maternal figure completed?

(1) Middle School/Junior High

(2) High School/GED

(3) Some College

(4) Associate's (two year) degree

(5) Bachelor's (four year) degree or higher

(6) Other/Unknown

8. What is your maternal figure's occupation? If your maternal figure is retired, please write her occupation before retirement. (Please write your response in the space below.) 
9. Who do you consider to be your primary paternal figure?

(1) Biological father

(2) Stepfather

(3) Grandfather

(4) Other (describe)

10. How many years did you live with your primary paternal figure between the ages of birth through the present?

(1) 0 years

(2) $1-5$ years

(3) 6-10 years

(4) $11-16$ years

11. Are you aware of any type of mental health concern(s) that your primary paternal figure experienced during your childhood?
(1) No
(2) Yes

12. If yes, check all mental health concerns applicable to that person:

(1) Depression

(2) Excessive worry and anxiety

(3) Anxiety in social situations

(4) Panic Attacks
(5) Alcohol Abuse

(6) Thoughts about suicide

(7) Other (describe)

13. What is the highest level of education your primary paternal figure completed?

(1) Middle School/Junior High

(2) High School/GED

(3) Some College

(4) Associate's (two year) degree

(5) Bachelor's (four year) degree or higher

(6) Other/Unknown

14. What is your paternal figure's occupation? If your paternal figure is retired, please write his occupation before retirement. (Please write your response in the space below.)

15. Are your primary maternal and paternal caregivers currently married to each other?
(1) No
(2) Yes

16. What is your sexual orientation?

(1) Heterosexual

(2) Homosexual

(3) Bisexual

(4) Other (describe)

17. What is your current dating status?

(1) I do not date.

(2) I date casually

(3) I am involved in a long-term monogamous relationship (duration 6 months or longer). 
18. Have you ever willingly had sexual intercourse (e.g., oral sex, anal penetration, or vaginal penetration)?

(1) No

(2) Yes

19. How old were you when you first willingly had sexual intercourse?

(1) Does not apply - I have never willingly had sexual intercourse.

(2) 13 years or younger

(3) 14

(4) 15

(5) 16

20. How many consensual (not forced) sexual partners have you had?

(1) 0

(2) 1

(5) 4

(3) 2

(6) 5

(4) 3

(7) 6

(8) 7 or more

21. How often do you drink alcohol? (Choose one)

(1) I never drink or have not drunk in the past year.

(2) I drink less than once a month, but at least once in the past year.

(3) I drink one to three times a month.

(4) I drink one to two times a week.

(5) I drink more than twice a week.

22. On a typical drinking occasion, how much do you usually drink? (Choose one)

(1) None

(2) Usually no more than 3 cans of beer (or 2 glasses of wine or 2 drinks of liquor)

(3) Usually no more than 4 cans of beer (or 3 glasses of wine or 3 drinks of liquor) liquor)

(4) Usually no more than 5 or 6 cans of beer (or 4 glasses of wine or 4 drinks of

(5) Usually more than 6 cans of beer (or 5 glasses of wine or 5 drinks of liquor)

23. In the last month, how often did you drink to the point of intoxication or drunkenness (that is, feeling dizzy, feeling ill, passing out, or feeling out of control)? (Choose one.

Estimate if you are unsure.)

(1) I never drank to the point of being drunk.

(2) I got drunk 1-3 times in the past month.

(3) I got drunk 4-5 times in the past month.

(4) I got drunk 6-10 times in the past month.

(5) I got drunk 11-15 times in the past month.

(6) I got drunk 16-20 times in the past month.

(7) I got drunk 21-25 times in the past month.

(8) I got drunk more than 25 times in the past month. 
24. Do you have an Individualized Education Plan (IEP)?

(1) No

(2) Yes

25. If you answered "yes" to question 24, why were you given an IEP? What accommodations were you given?

26. Have you ever received services from a mental health professional (e.g., social worker, counselor, psychologist, psychiatrist)?

(1) No

(2) Yes

27. If you answered "yes" to question 26, please describe why you saw a mental health professional (e.g., social worker, counselor, psychologist, psychiatrist).

28. What is your relation to

(1) Sister

(2) Cousin

(3) Friend 
Appendix B

Child Sexual Victimization Questionnaire

Many people have sexual experiences as children, either with friends or with people older than themselves. The following questions ask about any experiences you may have had.

Please check "no" or "yes" to whether or not you have had each of these experiences.

Then answer the questions below each experiences referring to the most significant time you had the experience.

FOR EACH ITEM, PLEASE CIRCLE YOUR ANSWER CHOICE.

1. Another person showed his/her sex organs to you.

(1) No

(2) Yes

1. Did you give your consent?
a. Yes
b. No

2. Who was involved? (Circle as many as apply.)

a. I did not have this experience

b. Stranger

c. Older person you knew (neighbor, teacher, friend of your parents, etc.)

d. Friend of your brother or sister, or person about your age (not boyfriend)

e. Aunt, uncle, or grandparent

f. Brother, step-brother; sister, or step-sister

g. Step-father or step-mother

h. Father or mother

i. Boyfriend

3. Approximately how old were you when it first happened?

a. I did not have this experience

b. 3-6 years

c. 7-10 years

d. 11-13 years

e. 14-16 years

4. Approximately how much older than you was the other person [If more than one person was involved, how much older was the oldest person?]

a. I did not have this experience

b. The person was younger than me or about my same age

c. The person was 1-4 years older than me

d. The person was 5-9 years older than me

e. The person was 10 or more years older than me

5. What is the main reason you participated?

a. I did not have this experience

b. Curiosity, it felt good, it made me feel loved or secure

c. Other person used his/her authority

d. Other person gave me gifts, money, candy, etc.

e. Other person threatened to hurt or punish me 
f. Other person used physical force

6. Did the other person use any of the following? (Circle all that apply)

a. I did not have this experience

b. Other person threatened to hurt or punish me

c. Other person used physical force

7. Another person showed his/her sex organs to me times. (Circle the number of times this occurred)
a. I did not have this experience
b. 1 time
c. 2-3 times
d. $4-5$ times
e. 6-7 times
f. More than 7 times

2. Someone older than you requested you to do something sexual. (1) No (2) Yes

1. Did you give your consent?
a. Yes
b. No

2. Who was involved? (Circle as many as apply.)

a. I did not have this experience

b. Stranger

c. Older person you knew (neighbor, teacher, friend of your parents, etc.)

d. Friend of your brother or sister, or person about your age (not boyfriend)

e. Aunt, uncle, or grandparent

f. Brother, step-brother; sister, or step-sister

g. Step-father or step-mother

h. Father or mother

i. Boyfriend

3. Approximately how old were you when it first happened?

a. I did not have this experience

b. 3-6 years

c. 7-10 years

d. 11-13 years

e. 14-16 years

4. Approximately how much older than you was the other person [If more than one person was involved, how much older was the oldest person?]

a. I did not have this experience

b. The person was younger than me or about my same age

c. The person was 1-4 years older than me

d. The person was 5-9 years older than me

e. The person was 10 or more years older than me

5. What is the main reason you participated?

a. I did not have this experience

b. Curiosity, it felt good, it made me feel loved or secure

c. Other person used his/her authority

d. Other person gave me gifts, money, candy, etc.

e. Other person threatened to hurt or punish me 
f. Other person used physical force

6. Did the other person use any of the following? (Circle all that apply)

a. I did not have this experience

b. Other person threatened to hurt or punish me

c. Other person used physical force

7. Another person requested that I do something sexual times this occurred)
a. I did not have this experience
b. 1 time
c. 2-3 times
d. $4-5$ times
e. 6-7 times
f. More than 7 times

3. You showed your sex organs to another person at his/her request. times. (Circle the number of

1. Did you give your consent?
a. Yes
b. No

2. Who was involved? (Circle as many as apply.)

a. I did not have this experience

b. Stranger

c. Older person you knew (neighbor, teacher, friend of your parents, etc.)

d. Friend of your brother or sister, or person about your age (not boyfriend)

e. Aunt, uncle, or grandparent

f. Brother, step-brother; sister, or step-sister

g. Step-father or step-mother

h. Father or mother

i. Boyfriend

3. Approximately how old were you when it first happened?

a. I did not have this experience

b. 3-6 years

c. 7-10 years

d. 11-13 years

e. 14-16 years

4. Approximately how much older than you was the other person [If more than one person was involved, how much older was the oldest person?]

a. I did not have this experience

b. The person was younger than me or about my same age

c. The person was 1-4 years older than me

d. The person was 5-9 years older than me

e. The person was 10 or more years older than me

5. What is the main reason you participated?

a. I did not have this experience

b. Curiosity, it felt good, it made me feel loved or secure

c. Other person used his/her authority

d. Other person gave me gifts, money, candy, etc.

e. Other person threatened to hurt or punish me 
f. Other person used physical force

6. Did the other person use any of the following? (Circle all that apply)

a. I did not have this experience

b. Other person threatened to hurt or punish me

c. Other person used physical force

7. I showed my sex organs at another person's request times this occurred)
a. I did not have this experience
b. 1 time
c. 2-3 times
d. $4-5$ times
e. 6-7 times
f. More than 7 times

4. Another person fondled you in a sexual way. times. (Circle the number of

1. Did you give your consent?
a. Yes
b. No

2. Who was involved? (Circle as many as apply.)
a. I did not have this experience
b. Stranger
c. Older person you knew (neighbor, teacher, friend of your parents, etc.)
d. Friend of your brother or sister, or person about your age (not boyfriend)
e. Aunt, uncle, or grandparent
f. Brother, step-brother; sister, or step-sister
g. Step-father or step-mother
h. Father or mother
i. Boyfriend

3. Approximately how old were you when it first happened?
a. I did not have this experience
b. 3-6 years
c. $7-10$ years
d. 11-13 years
e. 14-16 years

4. Approximately how much older than you was the other person [If more than one person was involved, how much older was the oldest person?]
a. I did not have this experience
b. The person was younger than me or about my same age
c. The person was 1-4 years older than me
d. The person was 5-9 years older than me
e. The person was 10 or more years older than me

5. What is the main reason you participated?

a. I did not have this experience

b. Curiosity, it felt good, it made me feel loved or secure

c. Other person used his/her authority

d. Other person gave me gifts, money, candy, etc. 
e. Other person threatened to hurt or punish me

f. Other person used physical force

6. Did the other person use any of the following? (Circle all that apply)

a. I did not have this experience

b. Other person threatened to hurt or punish me

c. Other person used physical force

7. Another person fondled me in a sexual way __ times. (Circle the number of times this occurred)
a. I did not have this experience
b. 1 time
c. 2-3 times
d. 4-5 times
e. 6-7 times
f. More than 7 times

5. Another person touched or stroked your sex organs.

(1) No

(2) Yes

1. Did you give your consent?
a. Yes
b. No

2. Who was involved? (Circle as many as apply.)
a. I did not have this experience
b. Stranger
c. Older person you knew (neighbor, teacher, friend of your parents, etc.)
d. Friend of your brother or sister, or person about your age (not boyfriend)
e. Aunt, uncle, or grandparent
f. Brother, step-brother; sister, or step-sister
g. Step-father or step-mother
h. Father or mother
i. Boyfriend

3. Approximately how old were you when it first happened?
a. I did not have this experience
b. 3-6 years
c. 7-10 years
d. 11-13 years
e. 14-16 years

4. Approximately how much older than you was the other person [If more than one person was involved, how much older was the oldest person?]

a. I did not have this experience

b. The person was younger than me or about my same age

c. The person was 1-4 years older than me

d. The person was 5-9 years older than me

e. The person was 10 or more years older than me

5. What is the main reason you participated?

a. I did not have this experience

b. Curiosity, it felt good, it made me feel loved or secure

c. Other person used his/her authority 
d. Other person gave me gifts, money, candy, etc.

e. Other person threatened to hurt or punish me

f. Other person used physical force

6. Did the other person use any of the following? (Circle all that apply)

a. I did not have this experience

b. Other person threatened to hurt or punish me

c. Other person used physical force

7. Another person touched or stroked my sex organs times. (Circle the number of times this occurred)

a. I did not have this experience

b. 1 time

c. 2-3 times

d. 4-5 times

e. 6-7 times

f. More than 7 times

6. You touched or stroked another person's sex organs at his/her request.

1. Did you give your consent?
a. Yes
b. No

2. Who was involved? (Circle as many as apply.)

a. I did not have this experience

b. Stranger

c. Older person you knew (neighbor, teacher, friend of your parents, etc.)

d. Friend of your brother or sister, or person about your age (not boyfriend)

e. Aunt, uncle, or grandparent

f. Brother, step-brother; sister, or step-sister

g. Step-father or step-mother

h. Father or mother

i. Boyfriend

3. Approximately how old were you when it first happened?

a. I did not have this experience

b. 3-6 years

c. 7-10 years

d. 11-13 years

e. 14-16 years

4. Approximately how much older than you was the other person [If more than one person was involved, how much older was the oldest person?]

a. I did not have this experience

b. The person was younger than me or about my same age

c. The person was 1-4 years older than me

d. The person was 5-9 years older than me

e. The person was 10 or more years older than me

5. What is the main reason you participated?

a. I did not have this experience

b. Curiosity, it felt good, it made me feel loved or secure

c. Other person used his/her authority 
d. Other person gave me gifts, money, candy, etc.

e. Other person threatened to hurt or punish me

f. Other person used physical force

6. Did the other person use any of the following? (Circle all that apply)

a. I did not have this experience

b. Other person threatened to hurt or punish me

c. Other person used physical force

7. I touched another person's sex organs at his/her request times. (Circle the number of times this occurred)
a. I did not have this experience
b. 1 time
c. 2-3 times
d. 4-5 times
e. 6-7 times
f. More than 7 times

7. Another person attempted intercourse (Got on top of you, attempted to insert penis but penetration did not occur).

(1) No

(2) Yes

1. Did you give your consent?
a. Yes
b. No

2. Who was involved? (Circle as many as apply.)

a. I did not have this experience

b. Stranger

c. Older person you knew (neighbor, teacher, friend of your parents, etc.)

d. Friend of your brother or sister, or person about your age (not boyfriend)

e. Aunt, uncle, or grandparent

f. Brother, step-brother; sister, or step-sister

g. Step-father or step-mother

h. Father or mother

i. Boyfriend

3. Approximately how old were you when it first happened?

a. I did not have this experience

b. 3-6 years

c. 7-10 years

d. 11-13 years

e. 14-16 years

4. Approximately how much older than you was the other person [If more than one person was involved, how much older was the oldest person?]

a. I did not have this experience

b. The person was younger than me or about my same age

c. The person was 1-4 years older than me

d. The person was 5-9 years older than me

e. The person was 10 or more years older than me

5. What is the main reason you participated?

a. I did not have this experience 
b. Curiosity, it felt good, it made me feel loved or secure

c. Other person used his/her authority

d. Other person gave me gifts, money, candy, etc.

e. Other person threatened to hurt or punish me

f. Other person used physical force

6. Did the other person use any of the following? (Circle all that apply)

a. I did not have this experience

b. Other person threatened to hurt or punish me

c. Other person used physical force

7. Another person attempted intercourse (Got on top of you, attempted to insert penis but penetration did not occur)_ times. (Circle the number of times this occurred)
b. 1 time
c. 2-3 times
d. $4-5$ times
e. 6-7 times
f. More than 7 times

a. I did not have this experience

8. Another person had intercourse (oral, anal, or vaginal) with you (any amount of penetration-ejaculation not necessary).

(1) No (2) Yes

1. Did you give your consent?
a. Yes
b. No

2. Who was involved? (Circle as many as apply.)

a. I did not have this experience

b. Stranger

c. Older person you knew (neighbor, teacher, friend of your parents, etc.)

d. Friend of your brother or sister, or person about your age (not boyfriend)

e. Aunt, uncle, or grandparent

f. Brother, step-brother; sister, or step-sister

g. Step-father or step-mother

h. Father or mother

i. Boyfriend

3. Approximately how old were you when it first happened?

a. I did not have this experience

b. 3-6 years

c. $7-10$ years

d. 11-13 years

e. 14-16 years

4. Approximately how much older than you was the other person [If more than one person was involved, how much older was the oldest person?]

a. I did not have this experience

b. The person was younger than me or about my same age

c. The person was 1-4 years older than me

d. The person was 5-9 years older than me

e. The person was 10 or more years older than me

5. What is the main reason you participated? 
a. I did not have this experience

b. Curiosity, it felt good, it made me feel loved or secure

c. Other person used his/her authority

d. Other person gave me gifts, money, candy, etc.

e. Other person threatened to hurt or punish me

f. Other person used physical force

6. Did the other person use any of the following? (Circle all that apply)

a. I did not have this experience

b. Other person threatened to hurt or punish me

c. Other person used physical force

7. Another person had intercourse (oral, anal, or vaginal) with you (any amount of penetration-ejaculation not necessary) times. (Circle the number of times this occurred)

a. I did not have this experience

b. 1 time

c. 2-3 times

d. $4-5$ times

e. 6-7 times

f. More than 7 times 
Appendix C

Risk Thermometer

\section{0: High Risk}

\section{5: Moderate Risk}

0: No Risk 
Appendix D

Video Coding System

\begin{tabular}{|c|c|c|}
\hline Outcome Measure & $\begin{array}{l}\text { Examples of Participant } \\
\text { Responses }\end{array}$ & Response Categories \\
\hline \multirow[t]{3}{*}{$\begin{array}{l}\text { 1.What would you do to cope } \\
\text { if you were in the situation? }\end{array}$} & 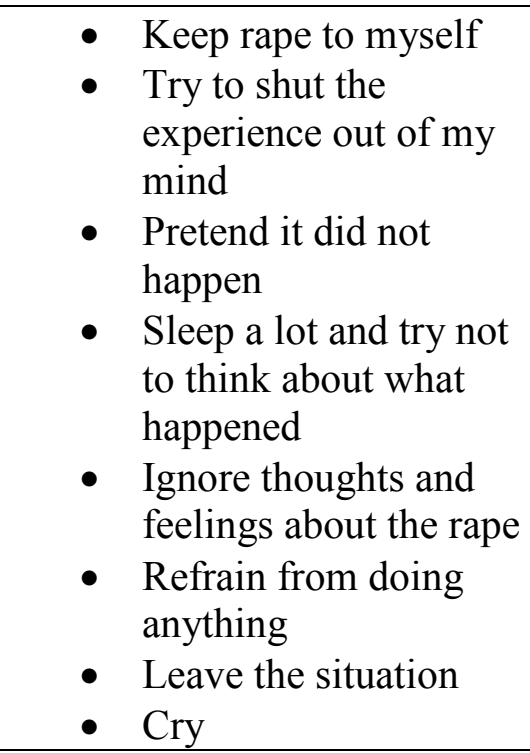 & Avoidance \\
\hline & $\begin{array}{ll}\text { - } & \text { Tell someone } \\
\text { - } & \text { Go get a friend } \\
\text { - } & \text { Call the police } \\
\text { - } & \text { Taking measures to be } \\
\text { more careful in the } \\
\text { future }\end{array}$ & Approach/Expressive \\
\hline & $\begin{array}{l}\text { - } \text { Take anti-anxiety drug } \\
\text { - Scared } \\
\text { - } \text { Be on the lookout for } \\
\text { future perpetrators } \\
\text { - } \quad \text { Thinking about the } \\
\text { event over and } \\
\text { over/ruminating } \\
\text { - Feel bad, sad, etc. }\end{array}$ & Nervous anxious \\
\hline
\end{tabular}

(Appendix continues) 
Appendix D (continued).

\begin{tabular}{|c|c|c|}
\hline Outcome Measure & $\begin{array}{l}\text { Examples of Participant } \\
\text { Responses }\end{array}$ & Response Categories \\
\hline \multirow[t]{3}{*}{$\begin{array}{l}\text { 1. What would you do to cope } \\
\text { if you were in the situation? }\end{array}$} & 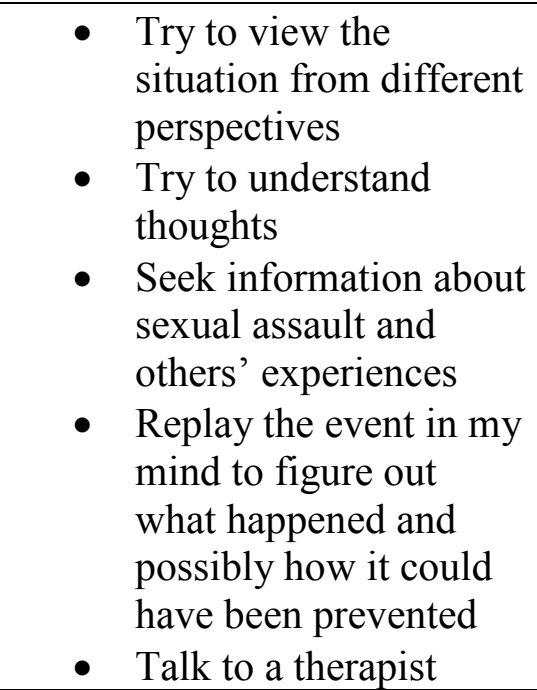 & Cognitive \\
\hline & $\begin{array}{ll}\text { - } & \text { Drink } \\
\text { - } & \text { Drugs } \\
\text { - } & \text { Suicide } \\
\text { - } & \text { Self-harm } \\
\end{array}$ & Self-Destructive behaviors \\
\hline & $\begin{array}{l}\text { Attempt to impose } \\
\text { harm to someone else } \\
\text { after the event } \\
\text { Attempt to have } \\
\text { another person cause } \\
\text { harm to someone else } \\
\text { after the event } \\
\text { Blaming others in an } \\
\text { attempt to get them in } \\
\text { trouble }\end{array}$ & $\begin{array}{l}\text { Other: Destructive Behaviors } \\
\text { towards others }\end{array}$ \\
\hline
\end{tabular}




\section{Appendix E}

\section{Risk Cues Contained in Each Scene}

\begin{tabular}{|c|c|}
\hline Scene & Risk Cues \\
\hline Acquaintance Rape & $\begin{array}{l}\text { - Parents do not know the main character } \\
\text { - } \text { is going to a party } \\
\text { - Male party attendee is getting beer with } \\
\text { a "bogus id" } \\
\text { - Male party attendee states that he hopes } \\
\text { to "get lucky" with the main character } \\
\text { - Male party attendee states that he has } \\
\text { been getting "pretty cozy" with the } \\
\text { main character when asked about his } \\
\text { intentions } \\
\text { - Drugs and alcohol are present at the } \\
\text { party } \\
\text { - Male party attendee states that he is } \\
\text { high } \\
\text { - Male party attendee asks the main } \\
\text { character to go to his room where no } \\
\text { one else is present } \\
\text { - Male party attendee pressures the main } \\
\text { character for sex even after she asks } \\
\text { him to stop }\end{array}$ \\
\hline Date Rape & $\begin{array}{l}\text { - Main character states that she has only } \\
\text { met the guy whose party she is } \\
\text { attending a couple of times } \\
\text { - No adults present at the party } \\
\text { - The main character is drinking } \\
\text { - The main character leaves her drink at } \\
\text { the table } \\
\text { - The male party attendee, with whom } \\
\text { she has been talking, puts something in } \\
\text { her drink } \\
\text { - The main character has difficulty } \\
\text { standing/walking } \\
\text { The male party attendee takes the main } \\
\text { character to a bedroom. No one else is } \\
\text { there. }\end{array}$ \\
\hline
\end{tabular}

(Appendix continues) 
Alcohol and Rape

Pressure for Sex

Pressure to Drink
- The main character is alone at a party

- There is heavy drinking at the party

- The main character is drinking alone

- No adults are present at the party

- The main character stumbles while walking

- The main character falls on a pool lounge chair.

- The main character passes out

- The male asks the girl if she gives head, whether she swallows, if she is a virgin, and to meet him in the basement during lunch the next day.

- The girl takes longer to respond with each proposition

- The girl shifts in her seat due to discomfort

- The girl takes deep breath

- The girl's facial expressions suggest she is uncomfortable with the situation

- The characters are at a house party with no adults present

- One of the characters wants to leave but his friends pressure him to drink one last drink

- The guy accepts the drink after stating that he needs to drive home

- The guy, who accepted the drink, begins to sweat

- The guy stumbles as he walks up the stairs

- The guy passes out on the bed

- The guy's friends fill up a tub with cold water to see if they can help their friend regain consciousness 


\section{Appendix F}

\section{Description of Video Scenes}

Acquaintance Rape (2:16): The scene begins with a female talking to one of her girlfriends about going to a house party. The main character reports that her mother does not know that she is going to the party and that her mother knows the host's parents are out of town. There are several people at the party and the scene depicts people drinking and doing drugs. When it becomes too loud, the guy, with whom she is with, invites her to his room to get away from the noise. Once in his room, the guy forces himself on the girl and proceeds to rape her even after she asks him to stop.

Date Rape (3:05): The scene begins with two girls walking to a house party being hosted by one of their brother's friends. When the two arrive to the party, they split up. The main character is shown hanging out and drinking with a guy at the party. When the girl leaves to go to the bathroom, the guy slips the date rape drug into her drink. The guy takes the girl to his room and rapes her once the drug has taken effect. The scene concludes with the girl crying after having been raped.

Alcohol and Rape (2:11): The scene begins at a party and shows a girl drinking an alcoholic beverage. The girl is alone at the party and does not socialize with anyone there. After walking through the party, the girl begins to stumble and passes out on a lounge chair by the pool. She wakes up the next morning and finds that her panties are on the floor and that she has been raped.

Pressure for Sex (2:44): This scene takes place during class in an alternative school. Throughout the scene, a guy passes notes to one of his female classmates. The note begins by asking her if she gives head and then asks her whether she swallows and if she is a virgin. With each note that she receives, the girl becomes more uncomfortable, as seen by her facial expressions and shifting in her chair. She also takes longer to respond to each note. The last note asks her to meet him in the basement the next day during lunch.

Pressure to Drink (2:00): The scene takes place in a house party setting and opens with two guys pressuring one of their male friends to drink. He initially refuses stating that he has to drive home, but eventually gives in and agrees to one drink. When his friends go back to the party, the guy gets progressively sick and sweaty. He finally passes out on a bed. His friends later find him passed out and put him in a tub of cold water. The guy never regains consciousness. The scene ends with his friends burying him. 
Appendix G

Parental Consent

\title{
WestVirginiaUniversity. \\ Office of Research Compliance
}

\section{PARENTAL OR GUARDIAN CONSENT AND INFORMATION FORM}

\author{
Parental Consent
}

Principal Investigator: Morris, Tracy

Department: $\quad$ ARTS \& SCIENCES - Psychology

Tracking Number: $\quad \mathrm{H}-22543$

Study Title:

Adjustment Among Adolescent Females

Co-Investigators(s):

Jones, Andrea, Ortega, Jonathan, Prout, Joanna

\section{Sponsor}

\section{Contact Persons}

In the event you experience any side effects or injury related to this research, you should contact Andrea M. Jones, M.S. at (304) 685-6403. For more information about this research and about research-related risks or injury, you can contact her supervisor Tracy Morris, PhD at (304) 293$2001 \times 31670$.

For information regarding your rights as a research subject, you may contact the Office of Research Compliance at 304/293-7073.

\section{Introduction}

Your child, , has been asked to participate in this research study, which has been explained to you by . This study is being conducted by Tracy, L. Morris, Ph.D., Andrea M. Jones, M.S., Jonathan Ortega, B. A., and Joanna Prout, M.S.W. in the department of Psychology at West Virginia University with funding provided by the Eberly College of Arts and Sciences and the Department of Psychology. This study is being done to fulfill the requirements of a dissertation in Psychology under the direction of Tracy L. Morris, Ph.D. 


\section{Purposes of the Study}

The purpose of this study is to develop a greater understanding of adolescent coping styles and risk recognition in social settings. You have been invited to participate in this research study, which involves answering questionnaires and watching short video vignettes. WVU expects to enroll approximately 48 subjects to participate in this study.

\section{Description of Procedures}

Once you and your child have consented/assented to participation in the research study, your child will complete the questionnaire measures. You will be asked to complete a short questionnaire. After completing the inventories, your child will be asked to watch five video vignettes ranging from 2-4 minutes. Your child will be instructed to stop the video at the point that she feels she would be too uncomfortable to remain in the situation and to give a rating on the risk thermometer. She will be allowed to view the rest of the scene after her response is recorded. After viewing the scene, your child will be asked to write a description of what she would do to cope in the same situation and what risk cues she saw in the video. Completion of the study will take approximately one hour. You may request to view the videos prior to your child's participation.

\section{Risks and Discomforts}

Your child will be presented with a series of questionnaires that may cause mild stress; however, any stress experienced is expected to be short in duration. A referral sheet including contact information for mental health providers in the area is being provided, should she wish to talk to a professional regarding stress experienced as a result of participation in the study.

\section{Alternatives}

Your child does not have to participate in this study.

There are no other alternatives

\section{Benefits}

Participation in this study may include the following benefits: increased access to physical/mental health services, insight into events and effects, and empowerment. If your child is being seen by a mental health professional, information collected during the study may be beneficial for treatment and can be shared with your child's therapist at your request. The knowledge gained from this study may also eventually benefit others.

\section{Financial Considerations}

Your child will receive $\$ 20$ for participating in the study.

\section{Confidentiality}

Any information about you that is obtained as a result of your participation in this research will be kept as confidential as is legally possible. Your research records and test results, just like hospital records, may be subpoenaed by court order or may be inspected by federal regulatory authorities without your consent. 
In addition, there are certain instances where the researcher is legally required to give information to the appropriate authorities. These would include mandatory reporting of information about behavior that is imminently dangerous to you or to others, such as suicide, child abuse, etc.

In any publications that result from this research, neither your child's name nor any information from which your child might be identified will be published without your consent.

We know that information about you and your health is private. We are dedicated to protecting the privacy of that information. Because of this promise, we must get your written authorization (permission) before we may use or disclose your protected health information or share it with others for research purposes. This form gives that permission. It also helps us make sure that you are correctly told how this information will be used or disclosed. Please read the information below carefully before signing this form. Please ask any questions you may have about this form or its uses. You can decide to sign or not to sign this authorization form. However, if you choose not to sign this authorization form, you will not be able to take part in the research study. Whatever choice you make about this research study, it will not have an effect on your medical care.

\section{USE AND DISCLOSURE COVERED BY THIS AUTHORIZATION}

DO NOT SIGN A BLANK FORM. You or your authorized representative should thoroughly read the information below before signing this form. Who will disclose, receive, and/or use the information? This form will authorize the following person(s), class(es) of persons, and/or organization(s) to disclose, use, and receive the information*:

The research site(s) carrying out this study. This includes UHA or UHA Affiliated, WVU, WVU Hospitals. It also includes each site's research staff and medical staff.

Health care providers who provide services to you as part of this research study.

Laboratories and other people and groups that look into your health information as part of this study in agreement with the study protocol.

The United States Department of Health and Human Services (which includes the National Institutes of Health, Food and Drug Administration (FDA)) and other groups that have the right to use the information as required by law.

* If, during the course of the research, one of the companies or institutions listed above merges with, or is purchased by, another company or institution, this authorization to use or disclose protected health information in the research will extend to the successor company or institution.

What information will be used or disclosed? 
Information provided to us on the demographic form, answers to the questionnaires, and responses to questions asked about the videos you are asked to watch may be disclosed in any of the instances previously discussed.

\section{SPECIFIC UNDERSTANDINGS}

By signing this research authorization form, you give permission for the use and/or disclosure of your protected health information described above. The purpose for the uses and disclosures you are authorizing is to carry out the research study explained to you during the informed consent process. It is also to ensure that the information relating to the research is available to all parties who may need it for research purposes. Your protected health information may be used as necessary for your research-related treatment or to collect payment for your research related treatment (when applicable). It may also be used to run the business operations of the institution.

This information may be disclosed or used for other purposes if a recipient described in this form is not required by law to protect the privacy of the information.

You have a right to refuse to sign this authorization. Your health care outside the study, the payment for your health care, and your health care benefits will not be affected if you do not sign this form. However, you will NOT be able to take part in the research study described in this authorization if you do not sign this form.

If you sign this authorization, you will have the right to cancel it at any time, except to the extent that UHA or UHA Affiliated, WVU, WVU Hospitals has already taken action based upon your authorization or needs the information to complete analysis reports of data for this research study. To cancel authorization, please write to the Principal Investigator, Tracy L. Morris, Ph.D. at: PO Box 6040; Morgantown, WV 26505.

You will not be allowed to see or copy the information described on this form as long as the research is in progress, but you have a right to see and copy the information upon completion of the research in accordance with hospital policies.

The members and staff of any Institutional Review Board (IRB) that oversees this research study:

The Principal Investigator: Tracy L. Morris, Ph.D. Members of UHA or UHA Affiliated, WVU, WVU Hospitals, administrative staff responsible for administering clinical trials and other research activities, including the Clinical Trials, Office/Office of Research and Sponsored Programs.

You have a right to receive a copy of this form after you have signed it.

Expiration Date: None

THE SUBJECT OR HIS/HER AUTHORIZED REPRESENTATIVE MUST BE PROVIDED WITH A COPY OF THIS FORM AFTER IT HAS BEEN SIGNED 


\section{SIGNATURE}

I have read this form and all of my questions about this form have been answered. By signing below, I acknowledge that I have read and accept all of the above.

Signature of Subject or Authorized Representative Date

Print Name of Subject or Authorized Representative

Relationship of the person signing as Subject or Authorized Representative above to the Subject

Print Name of Individual Explaining this Research Authorization Form

\section{CONTACT INFORMATION}

The contact information of the subject or authorized representative who signed this form should be filled in below.

Address:

Telephone:

(daytime)

(evening)

E-mail Address (optional):

\section{Voluntary Participation}

Participation in this study is voluntary.

You or your child may refuse to participate in this study. You or your child may withdraw from this study at any time.

Refusal to participate or withdrawal will involve no penalty to you or your child.

In the event new information becomes available that may affect your willingness to allow your child to participate in this study, this information will be given to you so that you can make an informed decision about whether or not to continue your child's participation.

Upon signing this form, you will receive a copy. 
I willingly consent to allow my child to participate in this research.

$\overline{\text { Signature of Parent or Guardian }} \overline{\text { Printed Name }} \overline{\text { Date }} \overline{\text { Time }}$

The parent/guardian has had the opportunity to have questions addressed. The parent/guardian willingly agrees to allow his/her child to be in the study.

Signature of Investigator or

Printed Name

Date

Time

Co-Investigator 
Appendix $\mathrm{H}$

Adolescent Assent

\section{WestVurginiaUniversity.}

Office of Research Compliance

\section{ASSENT FORM}

\section{Adolescent Assent}

Principal Investigator: Morris, Tracy

Department: $\quad$ ARTS \& Sciences - Psychology

Tracking Number: $\mathrm{H}-22543$

\section{Study Title:}

Adjustment Among Adolescent Females

\section{Co-Investigators:}

Jones, Andrea, Ortega, Jonathan, Prout, Joanna

\section{Sponsor}

\section{Contact Persons:}

In the event you experience any side effects or injury related to this research, you should contact Andrea M. Jones at (304) 685-6403. For more information about this research and about research-related risks or injury, you can contact her supervisor Tracy L. Morris, PhD at (304) 293-2001 x31670.

For information about your rights as a research subject, you may contact the Office of Research Compliance at 304/293-7073

\section{Introduction}

You, , have been asked to be in this research

study, which has been explained to you by

\section{Purposes of the Study}

The purpose of this study is to develop a greater understanding of adolescent coping styles and risk recognition in social settings. You have been invited to participate in this research study, which involves answering questionnaires and watching short video vignettes. WVU expects to enroll approximately 48 subjects to participate in this study. 


\section{Description of Procedures}

Once you and your parent/caregiver have consented/assented to participation in the research study, you will complete the questionnaire measures. Your parent/caregiver will complete a short questionnaire. After completing the inventories, you will be asked to watch five video vignettes ranging from 2-4 minutes. You will be instructed to stop the video at the point that you feel you would be too uncomfortable to remain in the situation and to give a rating on the risk thermometer. You will be allowed to view the rest of the scene after your response is recorded. After viewing the scene, you will be asked to write a description of what you would do to cope in the same situation and what risk cues you saw in the video. Completion of the study will take approximately one hour.

\section{Discomforts}

You will be presented with a series of questionnaires that may cause mild stress; however, any stress experienced is expected to be short in duration. A referral sheet including contact information for mental health providers in the area is being provided, should you wish to talk to a professional regarding stress experienced as a result of participation in the study.

\section{Benefits}

Participation in this study may include the following benefits: increased access to physical/mental health services, insight into events and their effects, and empowerment. If you are being seen by a mental health professional, information collected during the study may be beneficial for treatment and can be shared with your therapist at your parent/caregiver's request. The knowledge gained from this study may also eventually benefit others.

\section{Confidentiality}

Any information about you that is obtained as a result of your participation in this research will be kept as confidential as legally possible. Your research records and test results, just like hospital records, may be subpoenaed by court order or may be inspected by federal regulatory authorities without your consent.

In addition, there are certain instances where the researcher is legally required to give information to the appropriate authorities. These would include mandatory reporting of information about behavior that is imminently dangerous to you or to others, such as suicide, child abuse, etc. in any publications that result from this research, neither you nor your name nor any information from which you might be identified will be published without your consent.

We know that information about you and your health is private. Because of this promise, we must get your written permission before we may use or disclose your protected health information or share it with others for research purposes.

We promise that anything we learn about you in this study will be kept as secret as possible. 


\section{Voluntary Participation}

You do not have to do this. No one will be mad at you if you refuse to do this or if you decide to quit. You have been allowed to ask questions about the research, and all of your questions were answered.

I willingly agree to be in this research.

Signature of Subject

The child has had the opportunity to have questions addressed. The child willingly agrees to be in the study.

Signature of Investigator or

Printed Name

Date

Time

Co-Investigator 
Table 1.

Psychometric Properties of Independent and Dependent Variables

Measure

Internal Consistency

How I Deal with Things

Cognitive

Expressive

Nervous/Anxious

Avoidant

Self-Destructive

Child PTSD Symptom Scale

PTSD Total Score

Severity Score

Beck Depression Inventory-II

Multidimensional Anxiety Scale for Children

Physical Symptoms

Harm Avoidance

Social Anxiety

Separation Anxiety

Social Phobia and Anxiety Inventory

Social Phobia

Agoraphobia 
Table 1 (continued)

Measure

Internal Consistency

Social Skills Improvement System-Student Rating Form

Communication

Cooperation

Assertion

Responsibility

Empathy

Engagement

Self-Control

Externalizing

Bullying

Hyperactivity/Inattention

Internalizing

Social Skills Improvement System-Parent Rating Form

Communication

Cooperation

Assertion

Responsibility

Empathy

Engagement

Self-Control 
Table 1 (continued).

Measure

Internal Consistency

Hyperactivity/Inattention

Externalizing

Internalizing

Bullying

Autism Spectrum Problem Behaviors

Autism Spectrum Social Skills
.78

.89

.89

.78

.79

.89 
Table 2 .

Descriptive Statistics for Measures with the Total Sample.

\begin{tabular}{|c|c|c|c|c|}
\hline Measure & $\mathrm{N}$ & M & $\mathrm{SD}$ & Range \\
\hline \multicolumn{5}{|l|}{ How I Deal with Things } \\
\hline Avoidance & 41 & 26.54 & 7.54 & $7-48$ \\
\hline Expressive & 41 & 26.68 & 8.25 & $7-46$ \\
\hline Nervous/Anxious & 41 & 14.07 & 4.44 & $6-27$ \\
\hline Cognitive & 41 & 26.85 & 7.31 & $7-40$ \\
\hline Self-Destructive & 41 & 13.83 & 5.16 & $6-30$ \\
\hline \multicolumn{5}{|l|}{ Child PTSD Symptom Scale } \\
\hline Total Score & 41 & 17.24 & 10.82 & $1-39$ \\
\hline Symptom Severity Level & 41 & 2.07 & 2.09 & $0-7$ \\
\hline Beck Depression Inventory & 41 & 11.88 & 9.58 & $0-45$ \\
\hline \multicolumn{5}{|c|}{ Multidimensional Anxiety Scale for Children } \\
\hline Physical Symptoms & 41 & 46.22 & 9.86 & $32-68$ \\
\hline Harm Avoidance & 41 & 49.07 & 11.07 & $25-77$ \\
\hline Social Anxiety & 41 & 49.44 & 11.46 & $32-79$ \\
\hline Separation Anxiety & 41 & 52.63 & 12.47 & $33-85$ \\
\hline Anxiety Disorders Index & 41 & 47.44 & 9.63 & $25-65$ \\
\hline Total Score & 41 & 47.88 & 10.11 & $25-69$ \\
\hline
\end{tabular}


Table 2 (continued).

Measure

$\mathrm{N} \quad \mathrm{M} \quad \mathrm{SD}$

Range

Social Phobia and Anxiety Inventory

Social Phobia

$\begin{array}{llll}41 & 65.17 & 33.90 & 1.20-135.80\end{array}$

Agoraphobia

$\begin{array}{lll}41 \quad 25.93 & 15.36\end{array}$

$0-73$

SPAI Difference Score

$\begin{array}{llll}41 & 39.24 & 26.72 & -2.50-90.85\end{array}$

Social Skills Improvement System-Student Rating Form

Communication

$\begin{array}{lll}41 & 78.56 & 8.40\end{array}$

$58-92$

Cooperation

$\begin{array}{lll}41 & 80.07 & 12.91\end{array}$

49-102

Assertion

$\begin{array}{lll}41 & 76.76 & 12.59\end{array}$

46-102

Responsibility

$\begin{array}{lll}41 & 84.22 \quad 11.37\end{array}$

49-102

Empathy

$\begin{array}{lll}41 & 76.44 & 10.95\end{array}$

49-92

Engagement

$\begin{array}{lll}41 & 94.95 & 13.60\end{array}$

68-114

Self-Control

$\begin{array}{lll}41 & 66.80 & 11.45\end{array}$

40-92

Externalizing

$\begin{array}{lll}41 & 64.20 & 19.58\end{array}$

40-127

Bullying

$41 \quad 46.44 \quad 7.09$

40-64

Hyperactivity/Inattention

$\begin{array}{lll}41 & 58.29 & 14.31\end{array}$

40-102

Internalizing

$\begin{array}{lll}41 & 58.24 & 12.72\end{array}$

40-89

Social Skills Improvement System-Parent Rating Form

Communication

$\begin{array}{lll}41 & 77.85 & 12.25\end{array}$

40-96

Cooperation

$\begin{array}{lll}41 & 69.63 & 11.88\end{array}$

$40-85$

(table continues) 
Table 2 (continued).

\begin{tabular}{lcccc}
\hline Measure & N & M & SD & Range \\
\hline Assertion & 41 & 73.51 & 12.57 & $40-102$ \\
Responsibility & 41 & 68.44 & 12.37 & $40-85$ \\
Empathy & 41 & 68.76 & 12.52 & $40-85$ \\
Engagement & 41 & 72.81 & 11.63 & $40-92$ \\
Self-Control & 41 & 64.41 & 13.95 & $40-96$ \\
Hyperactivity/Inattention & 41 & 47.10 & 8.87 & $40-68$ \\
Externalizing & 41 & 54.98 & 16.83 & $40-102$ \\
Internalizing & 41 & 52.73 & 14.58 & $40-96$ \\
Bullying & 41 & 40.73 & 2.23 & $40-51$ \\
Autism Spectrum Problem Behaviors & 41 & 44.41 & 7.67 & $40-68$ \\
Autism Spectrum Social Skills & & 85.88 & 13.90 & $40-106$ \\
\hline
\end{tabular}


Table 3.

Descriptive Statistics for Measures with the Target Sample.

\begin{tabular}{|c|c|c|c|c|}
\hline Measure & $\mathrm{N}$ & M & SD & Range \\
\hline \multicolumn{5}{|l|}{ How I Deal with Things } \\
\hline Avoidance & 17 & 28.00 & 8.92 & $15-48$ \\
\hline Expressive & 17 & 25.94 & 9.00 & $12-46$ \\
\hline Nervous/Anxious & 17 & 15.24 & 4.76 & $7-27$ \\
\hline Cognitive & 17 & 25.82 & 5.29 & $14-35$ \\
\hline Self-Destructive & 17 & 13.94 & 5.40 & $8-26$ \\
\hline \multicolumn{5}{|l|}{ Child PTSD Symptom Scale } \\
\hline Total Score & 17 & 17.76 & 10.82 & $2-39$ \\
\hline Symptom Severity Level & 17 & 2.18 & 2.03 & $0-6$ \\
\hline Beck Depression Inventory & 17 & 13.59 & 11.98 & $0-45$ \\
\hline \multicolumn{5}{|c|}{ Multidimensional Anxiety Scale for Children } \\
\hline Physical Symptoms & 17 & 44.35 & 9.29 & $32-65$ \\
\hline Harm Avoidance & 17 & 47.59 & 9.43 & $28-64$ \\
\hline Social Anxiety & 17 & 50.47 & 13.33 & $32-79$ \\
\hline Separation Anxiety & 17 & 50.24 & 14.31 & $33-85$ \\
\hline Anxiety Disorders Index & 17 & 47.53 & 11.00 & $25-65$ \\
\hline Total Score & 17 & 46.82 & 11.70 & $25-69$ \\
\hline
\end{tabular}


Table 3 (continued).

Measure

$\mathrm{N} \quad \mathrm{M} \quad \mathrm{SD}$

Range

Social Phobia and Anxiety Inventory

Social Phobia

$17 \quad 59.12 \quad 34.43 \quad 1.20-127.45$

Agoraphobia

$17 \quad 24.76 \quad 19.17$

$0-73$

SPAI Difference Score

$\begin{array}{llll}17 & 34.35 & 22.93 & -2.37-68.45\end{array}$

Social Skills Improvement System-Student Rating Form

Communication

$17 \quad 79.41-8.48$

$64-92$

Cooperation

$\begin{array}{lll}17 & 79.82 & 14.09\end{array}$

55-102

Assertion

$17 \quad 77.12 \quad 13.97$

46-96

Responsibility

$\begin{array}{lll}17 & 85.47 & 11.01\end{array}$

61-102

Empathy

$\begin{array}{lll}17 & 78.47 & 10.06\end{array}$

$58-92$

Engagement

$\begin{array}{lll}17 & 93.59 & 14.77\end{array}$

68-111

Self-Control

$\begin{array}{lll}17 & 67.76 & 9.85\end{array}$

$52-86$

Externalizing

$\begin{array}{lll}17 & 60.88 & 19.69\end{array}$

$40-96$

Bullying

$17 \quad 44.94 \quad 6.62$

$40-64$

Hyperactivity/Inattention

$\begin{array}{lll}17 & 56.18 & 14.22\end{array}$

$40-83$

Internalizing

$\begin{array}{lll}17 & 57.59 & 14.75\end{array}$

$40-86$

Social Skills Improvement System-Parent Rating Form

Communication

$\begin{array}{lll}17 & 76.53 & 12.09\end{array}$

$40-92$

Cooperation

$\begin{array}{lll}17 & 69.35 & 12.32\end{array}$

40-82

(table continues) 
Table 3 (continued).

\begin{tabular}{lcccc}
\hline Measure & N & M & SD & Range \\
\hline Assertion & 17 & 73.71 & 14.81 & $40-96$ \\
Responsibility & 17 & 67.18 & 13.34 & $40-85$ \\
Empathy & 17 & 69.12 & 13.84 & $40-85$ \\
Engagement & 17 & 72.94 & 12.00 & $40-92$ \\
Self-Control & 17 & 62.06 & 15.17 & $40-85$ \\
Hyperactivity/Inattention & 17 & 49.06 & 11.38 & $40-68$ \\
Externalizing & 17 & 58.35 & 23.05 & $40-102$ \\
Internalizing & 17 & 48.76 & 19.25 & $40-96$ \\
Bullying & 17 & 41.64 & 3.28 & $40-51$ \\
Autism Spectrum Problem Behaviors & 17 & 47.47 & 10.34 & $40-68$ \\
Autism Spectrum Social Skills & & 84.59 & 15.34 & $40-106$ \\
\hline
\end{tabular}


Table 4.

Descriptive Statistics for Measures with the Comparison Sample.

\begin{tabular}{|c|c|c|c|c|}
\hline Measure & $\mathrm{N}$ & $\mathrm{M}$ & SD & Range \\
\hline \multicolumn{5}{|l|}{ How I Deal with Things } \\
\hline Avoidance & 24 & 25.50 & 6.39 & $7-36$ \\
\hline Expressive & 24 & 27.21 & 7.82 & $7-42$ \\
\hline Nervous/Anxious & 24 & 13.25 & 4.09 & $6-23$ \\
\hline Cognitive & 24 & 27.58 & 8.49 & $7-40$ \\
\hline Self-Destructive & 24 & 13.75 & 5.09 & $6-30$ \\
\hline \multicolumn{5}{|l|}{ Child PTSD Symptom Scale } \\
\hline Total Score & 24 & 16.87 & 11.03 & $1-33$ \\
\hline Symptom Severity Level & 24 & 2.00 & 2.17 & $0-7$ \\
\hline Beck Depression Inventory & 24 & 10.66 & 7.48 & $2-33$ \\
\hline \multicolumn{5}{|c|}{ Multidimensional Anxiety Scale for Children } \\
\hline Physical Symptoms & 24 & 47.54 & 10.23 & $33-68$ \\
\hline Harm Avoidance & 24 & 50.13 & 12.19 & $25-77$ \\
\hline Social Anxiety & 24 & 48.71 & 10.17 & $32-68$ \\
\hline Separation Anxiety & 24 & 54.33 & 10.99 & $38-76$ \\
\hline Anxiety Disorders Index & 24 & 47.38 & 8.78 & $27-63$ \\
\hline Total Score & 24 & 48.63 & 9.02 & $33-69$ \\
\hline
\end{tabular}

(table continues) 
Table 4 (continued).

Measure

$\mathrm{N} \quad \mathrm{M} \quad \mathrm{SD}$

Range

Social Phobia and Anxiety Inventory

Social Phobia

Agoraphobia

SPAI Difference Score

Social Skills Improvement System-Student Rating Form

Communication

Cooperation

Assertion

Responsibility

Empathy

Engagement

Self-Control

Externalizing

Bullying

Hyperactivity/Inattention

Internalizing

Social Skills Improvement System-Parent Rating Form
$24 \quad 69.45 \quad 33.59 \quad 11.83-135.80$

$\begin{array}{llll}24 & 26.75 & 12.38 & 9-54\end{array}$

$\begin{array}{llll}24 & 42.70 & 29.09 & -2.50-90.85\end{array}$

$\begin{array}{llll}24 & 78.29 & 8.48 & 58-92\end{array}$

$\begin{array}{llll}24 & 80.25 & 12.31 \quad 49-96\end{array}$

$\begin{array}{llll}24 & 76.50 & 11.83 & 46-102\end{array}$

$\begin{array}{lll}24 & 83.33 & 11.76\end{array}$

49-99

$24 \quad 75.00 \quad 11.53$

$49-92$

$\begin{array}{lll}24 & 94.92 & 12.95\end{array}$

68-114

$\begin{array}{lll}24 & 66.13 & 12.62\end{array}$

$40-92$

$\begin{array}{lll}24 & 66.54 & 19.58\end{array}$

43-127

$24 \quad 47.50 \quad 7.35$

$40-64$

$\begin{array}{lll}24 & 59.79 & 14.49\end{array}$

40-102

$\begin{array}{lll}24 & 58.71 & 11.37\end{array}$

$40-89$
Communication
Cooperation
$\begin{array}{lll}24 & 78.79 & 12.54\end{array}$
54-96
$\begin{array}{lll}24 & 69.83 & 11.83\end{array}$
44-85

(table continues) 
Table 4 (continued).

\begin{tabular}{lcccc}
\hline Measure & N & M & SD & Range \\
\hline Assertion & 24 & 73.38 & 11.06 & $54-102$ \\
Responsibility & 24 & 69.33 & 11.85 & $44-85$ \\
Empathy & 24 & 68.50 & 11.81 & 44.85 \\
Engagement & 24 & 72.67 & 11.62 & $44-89$ \\
Self-Control & 24 & 66.08 & 13.09 & $41-96$ \\
Hyperactivity/Inattention & 24 & 45.71 & 6.47 & $40-58$ \\
Externalizing & 24 & 52.58 & 10.42 & $40-72$ \\
Internalizing & 24 & 48.46 & 8.12 & $40-65$ \\
Bullying & 24 & 40.08 & .28 & $40-41$ \\
Autism Spectrum Problem Behaviors & 24 & 42.25 & 4.02 & $40-54$ \\
Autism Spectrum Social Skills & 24 & 86.79 & 13.06 & $58-106$ \\
\hline
\end{tabular}


Table 5 .

Descriptive Statistics for Vignettes with the Total Sample

\begin{tabular}{lcccr}
\hline Vignette & $\mathrm{N}$ & $\mathrm{M}$ & $\mathrm{SD}$ & Range \\
\hline Approach Expressive & 41 & 4.51 & 2.39 & $0-10$ \\
Nervous Anxious & 41 & .26 & .55 & $0-2$ \\
Cognitive Coping & 41 & .80 & 1.23 & $0-4$ \\
Self-Destructive & 41 & .12 & .56 & $0-3$ \\
Avoidant & 41 & 2.98 & 2.40 & $0-10$ \\
\hline
\end{tabular}


Table 6.

Descriptive Statistics for Vignettes with the Target Sample

\begin{tabular}{lcccc}
\hline Vignette & N & M & SD & Range \\
\hline Approach Expressive & 17 & 4.76 & 2.02 & $1-9$ \\
Nervous Anxious & 17 & .24 & .56 & $0-2$ \\
Cognitive Coping & 17 & 1.24 & 1.56 & $0-4$ \\
Self-Destructive & 17 & .29 & .85 & $0-3$ \\
Avoidant & 17 & 2.42 & 1.80 & $0-7$ \\
\hline
\end{tabular}


Table 7 .

Descriptive Statistics for Vignettes with the Comparison Sample

\begin{tabular}{lcccc}
\hline Vignette & $\mathrm{N}$ & $\mathrm{M}$ & $\mathrm{SD}$ & Range \\
\hline Approach Expressive & 24 & 4.33 & 2.65 & $0-10$ \\
Nervous Anxious & 24 & .29 & .55 & $0-2$ \\
Cognitive Coping & 24 & .50 & .83 & $0-3$ \\
Self-Destructive & 24 & .00 & .00 & $0-0$ \\
Avoidant & 24 & 3.38 & 2.72 & $0-10$ \\
\hline
\end{tabular}


Table 8. Participant Demographics

Characteristic

Frequency

Percentage

Target Ethnic Group Identity

Caucasian (non Hispanic)

10

African American (non Hispanic)

5

29.4

Multiracial

2

11.8

Comparison Ethnic Group Identity

Caucasian (non Hispanic)

African American (non Hispanic)

7

Multiracial

Other

Target Maternal Figure

Biological Mother

Stepmother

Other

Comparison Maternal Figure

Biological Mother

Grandmother

Other 
Table 8 (continued).

Characteristic

Frequency

Percentage

Target Years with Mother

0 years

$1-5$ years

2

11.8

11-16 years

14

Comparison Years with Mother

0 years

11-16 years

Target Maternal Mental Health Concerns

No

Yes

Comparison Maternal Mental Health Concerns

No

Yes

3

Target Maternal Education Level

Middle School/Junior High

High School/GED

6

Associate's Degree

Bachelor's Degree or Higher

4

23.5

(table continues) 
Table 8 (continued).

Characteristic

Frequency

Percentage

Other

1

Comparison Maternal Education Level

Middle School/Junior High

1

High School/GED

5

20.8

Some College

3

Associate's Degree

4

16.7

Bachelor's Degree or Higher

10

Other/Unknown

Target Paternal Figure

Biological Father

9

Stepfather

4

Other

4

Comparison Paternal Figure

Biological Father

19

79.2

Stepfather

1

Grandfather

2

Other

2

Target Years with Father

0 years

2

11.8

$1-5$ years

3

17.6

(table continues) 
Table 8 (continued).

Characteristic

Frequency

Percentage

6-10 years

1

$11-16$ years

11

64.7

Target Paternal Mental Health Concerns

No

13

Yes

4

Comparison Paternal Mental Health Concerns

No

Yes

Target Paternal Education Level

High School/GED

Some College

Associate's Degree

Bachelor's Degree or Higher

Other/Unknown

Comparison Paternal Education Level

Middle School/Junior High

High School/GED

Some College

Associate's Degree

Bachelor's Degree or Higher

9

37.5 
Table 9.

Social History

Characteristic

Frequency

Percentage

Other/Unknown

1

Target Sexual Orientation

Heterosexual

Bisexual

Comparison Sexual Orientation

Heterosexual

18

Homosexual

1

Bisexual

3

Target Current Dating Status

Not Dating

4

Date Casually

12

70.6

Monogamous relationship ( $>6$ months)

Comparison Current Dating Status

Not Dating

Date Casually

16

66.7

Monogamous relationship ( $>6$ months)

2

Target Consensual Intercourse

No

7

Yes

10

58.8

(table continues) 
Table 9 (continued).

Characteristic

Frequency

Percentage

Comparison Consensual Intercourse

No

17

70.8

Yes

7

Target Age of Consensual Intercourse

N/A

7

13 years old

2

11.8

14 years old

4

15 years old

3

17.6

16 years old

1

Comparison Age of Consensual Intercourse

N/A

17

70.8

14 years old

2

8.3

15 years old

3

Target Number of Consensual Partners

0 partners

11

1 partner

2

11.8

2 partners

3

17.6

3 partners

1

5.9

(table continues) 
Table 9 (continued).

Characteristic

Frequency Percentage

Comparison Number of Consensual Partners

0 partners

17

70.8

1 partner

2

2 partners

3

3 partners

1

4 partners

1

Target Frequency of Alcohol Intake

0 drinks in past year

13

76.5

Less than once/month, but at least once in past year

2

11.8

1-3 times/month

1-2 times/week

Comparison Frequency of Alcohol Intake

0 drinks in past year

Less than once/month, but at least once in past year

1-2 times/week

Target Amount Consumed on Drinking Occasion

None

$\leq 3$ cans of beer (or 2 glasses of wine or 2 drinks of liquor)

$\leq 4$ cans of beer (or 3 glasses of wine or 3 drinks of liquor)

$\geq 6$ cans of beer (or 5 glasses of wine or 5 drinks of liquor) 
Table 9 (continued).

Characteristic

Frequency Percentage

Comparison Amount Consumed on Drinking Occasion

None

$\leq 3$ cans of beer (or 2 glasses of wine or 2 drinks of liquor)

$\leq 4$ cans of beer (or 3 glasses of wine or 3 drinks of liquor)
18

5

1

17

100

Comparison Number of Times Drunk in Past Month

Never became drunk

22

2

$1-3$ times in past month

Target IEP

No

Yes

Comparison IEP

No

Target Mental Health

No

Yes
22

2

6

13

4

11

64.7 
Table 9 (continued).

Characteristic

Frequency

Percentage

Comparison Mental Health

No

70.8

Yes

7

29.2 
Table 10.

Abuse History in the Target Group

Type of Abuse

Total Endorsed

Total Percentage

1. Perpetrator showed victim sexual organs

No Consent Given

Perpetrator Identity

Known older person (neighbor, teacher,

friend of parents, etc.)

Friend of brother, sister, or person of

same age (not boyfriend)

Brother, step-brother, sister, step-sister

Boyfriend

2

Age of Victim

3-6 years old

11-13 years old

$14-16$

2

28.6

Age of Perpetrator

Younger or about my age

1

1-4 years older

3

5-9 years older

1

14.3

10 or more years older

2

28.6

(table continues) 
Table 10 (continued).

Type of Abuse

Total Endorsed

Total Percentage

Reason for participation

Curiosity, felt good, made me feel loved

4

or secure

Perpetrator authority

1

Perpetrator gave gifts, money, candy

1

Perpetrator hurt or punished me

Perpetrator used physical Force

Perpetrator threatened to hurt or punish

me

Perpetrator threatened physical force

Number of times event experienced

I did not have this experience

1

1 time

2

28.6

2-3 times

2

28.6

6-7 times

1

2. Someone older requested I do something sexual

No Consent Given

Perpetrator Identity

Stranger

Known older person (neighbor, teacher, friend of parents, etc.)
1

4

40.0 
Table 10 (continued).

Type of Abuse

Total Endorsed Total Percentage

Friend of brother, sister, or person of

same age (not boyfriend)

Brother, step-brother, sister, step-sister

1

10.0

Step-father or step-mother

1

10.0

Boyfriend

1

10.0

Other

1

10.0

Age of Victim

3-6 years old

20.0

7-10 years old

2

10.0

11-13 years old

2

20.0

14-16

5

50.0

Age of Perpetrator

Younger or about my age

10.0

1-4 years older

50.0

5-9 years older

10.0

10 or more years older

30.0

Reason for participation

Curiosity, felt good, made me feel loved

1

10.0

or secure

Perpetrator authority

1

10.0

Perpetrator gave gifts, money, candy

2

20.0

(table continues) 
Table 10 (continued).

Type of Abuse

Total Endorsed

Total Percentage

Perpetrator hurt or punished me

2

20.0

Perpetrator used physical Force

3

30.0

Perpetrator threatened to hurt or punish

4

40.0

me

Perpetrator threatened physical force

4

40.0

Number of times event experienced

I did not have this experience

1 time

2

20.0

2-3 times

4

40.0

6-7 times

1

10.0

More than 7 times

1

10.0

3. Showed sexual organs at perpetrator's request

No Consent Given

Perpetrator Identity

I did not have this experience 1

Known older person (neighbor, teacher,

friend of parents, etc.)

Friend of brother, sister, or person of same age (not boyfriend)

Brother, step-brother, sister, or step-sister

1

(table continues) 
Table 10 (continued).

Type of Abuse

Total Endorsed

Total Percentage

Boyfriend

1

20.0

Age of Victim

I did not have this experience

3-6 years old

7-10 years old

11-13 years old

14-16

Age of Perpetrator

I did not have this experience

Younger or about my age

20.0

1-4 years older

40.0

5-9 years older

Reason for participation

Curiosity, felt good, made me feel loved or 20.0 secure

Perpetrator authority

1

20.0

Perpetrator gave gifts, money, candy

1

20.0

Perpetrator hurt or punished me

1

20.0

Perpetrator used physical Force

1

20.0

Perpetrator threatened to hurt or punish me

3

60.0 
Table 10 (continued).

Type of Abuse

Total Endorsed Total Percentage

Perpetrator threatened physical force

1

20

Number of times event experienced

I did not have this experience

1

20

1 time

1

20

2-3 times

2

40

More than 7 times

1

20

4. Perpetrator fondled the victim

No Consent Given

Perpetrator Identity

Known older person (neighbor, teacher,

friend of parents, etc.)

Friend of brother, sister, or person of

same age (not boyfriend)

Brother, step-brother, sister, or step-sister

Step-father or step-mother

Boyfriend

Age of Victim

3-6 years old

7-10 years old 
Table 10 (continued).

Type of Abuse

Total Endorsed Total Percentage

11-13 years old

3

33.3

14-16 years old

4

44.4

Age of Perpetrator

Younger or about my age

3

1-4 years older

3

5-9 years older

2

10 or more years older

1

11.1

Reason for participation

Curiosity, felt good, made me feel loved

or secure

Perpetrator authority

Perpetrator gave gifts, money, candy

1

11.1

Perpetrator hurt or punished me

2

Perpetrator used physical Force

1

11.1

Perpetrator threatened to hurt or punish

4

me

Perpetrator threatened physical force

3

Number of times event experienced

1 time

2-3 times

3

More than 7 times 
Table 10 (continued).

Type of Abuse

Total Endorsed Total Percentage

5. Perpetrator touched/stroked victim's sex organs

No Consent Given

Perpetrator Identity

Stranger

Known older person (neighbor, teacher,

friend of parents, etc.)

Friend of brother, sister, or person of

same age (not boyfriend)

Brother, step-brother, sister, or step-sister

2

Boyfriend

1

14.3

Other

1

Age of Victim

3-6 years old

1

7-10 years old

1

11-13 years old

2

14-16 years old

3

Age of Perpetrator

Younger or about my age

1-4 years older

3

5-9 years older

2

28.6

(table continues) 
Table 10 (continued).

Type of Abuse

Total Endorsed Total Percentage

Reason for participation

Perpetrator authority

1

14.3

Perpetrator gave gifts, money, candy

1

14.3

Perpetrator hurt or punished me

3

Perpetrator used physical Force

2

28.6

Perpetrator threatened to hurt or punish

3

me

Perpetrator threatened physical force

Number of times event experienced

I did not have this experience

1 time

2-3 times

2

More than 7 times

6. Victim touched/stroked perpetrator's sex organs at perpetrator's request

No Consent Given

Perpetrator Identity

Friend of brother, sister, or person of

same age (not boyfriend)

Brother, step-brother, sister, or step-sister 
Table 10 (continued).

Type of Abuse

Total Endorsed Total Percentage

Age of Victim

7-10 years old

1

11-13 years old

1

14-16 years old

1

Age of Perpetrator

1-4 years older

1

5-9 years older

1

10 or more years older

1

Reason for participation

Perpetrator hurt or punished me

2

Perpetrator threatened to hurt or punish

me

Number of times event experienced

I did not have this experience

1

2-3 times

1

More than 7 times

1

7. Perpetrator attempted intercourse (no penetration)

No Consent Given

17.6

(table continues) 
Table 10 (continued).

Type of Abuse

Total Endorsed

Total Percentage

Perpetrator Identity

Known older person (neighbor, teacher,

2

friend of parents, etc.)

Brother, step-brother, sister, or step-sister

1

Age of Victim

3-6 years old

1

7-10 years old

1

11-13 years old

1

Age of Perpetrator

I did not have this experience

1

Younger or about my age

1

1-4 years older

1

Reason for participation

Perpetrator authority

Perpetrator gave gifts, money, candy

1

Perpetrator used physical Force

1

Perpetrator threatened to hurt or punish

2

me

Perpetrator threatened physical force 
Table 10 (continued).

Type of Abuse

Total Endorsed Total Percentage

Number of times event experienced

1 time

2-3 times

1

More than 7 times

1

8. Intercourse (oral, anal, vaginal; ejaculation not necessary)

No Consent Given

Perpetrator Identity

I did not have this experience

Brother, step-brother, sister, or step-sister

Boyfriend

Other

1

Age of Victim

7-10 years old

14-16 years old

Age of Perpetrator

I did not have this experience

Younger or about my age

1

1-4 years older

1

5-9 years older

1

25.0 
Table 10 (continued).

Type of Abuse

Total Endorsed

Total Percentage

Reason for participation

Curiosity, felt good, made me feel loved

1

25.0

or secure

Perpetrator gave gifts, money, candy

1

Perpetrator hurt or punished me

1

Perpetrator threatened to hurt or punish

2

50.0

me

Number of times event experienced

1 time

1

4-5 times

1

25.0

More than 7 times

1

25.0 
Table 11.

Correlations among Abuse Severity, Latency, and Identified Risk Cues in the Total Sample

\begin{tabular}{|c|c|c|c|}
\hline & Abuse Severity & Latency & Risk Cues \\
\hline Abuse Severity & 1.00 & -.18 & $.47 * *$ \\
\hline Latency & & 1.00 & $-.36^{*}$ \\
\hline Risk Cues & & & 1.00 \\
\hline
\end{tabular}


Table 12.

Correlations among Abuse Severity, Latency, and Identified Risk Cues in the Target Sample

\begin{tabular}{|c|c|c|c|}
\hline & Abuse Severity & Latency & Risk Cues \\
\hline Abuse Severity & 1.00 & -.18 & $.43 *$ \\
\hline Latency & & 1.00 & $-.62 * *$ \\
\hline Risk Cues & & & 1.00 \\
\hline
\end{tabular}


Table 13.

Correlations among Abuse Severity, Latency, and Identified Risk Cues in the Comparison Sample.

\begin{tabular}{|c|c|c|c|}
\hline & Abuse Severity & Latency & Risk Cues \\
\hline Abuse Severity & 1.00 & .01 & $.59 * *$ \\
\hline Latency & & 1.00 & -.18 \\
\hline Risk Cues & & & 1.00 \\
\hline
\end{tabular}


Table 14.

Correlations between Student-Rated Social Skills and Risk Perception Using the Total Sample

\begin{tabular}{|c|c|c|c|c|c|c|c|c|c|c|c|}
\hline & 1 & 2 & 3 & 4 & 5 & 6 & 7 & 8 & 9 & 10 & 11 \\
\hline 1. Communication & 1.00 & $.67 * *$ & $.42 * *$ & $.60 * *$ & $.58 * *$ & $.42 * *$ & $.38 * *$ & .01 & .17 & .15 & $.74 * *$ \\
\hline 2. Cooperation & & 1.00 & $.42 * *$ & $.73 * *$ & $.56^{* *}$ & $.40 * *$ & $.49 * *$ & .24 & -.07 & .18 & $.80 * *$ \\
\hline 3. Assertion & & & 1.00 & $.30 *$ & $.54 * *$ & $.68 * *$ & $.43 * *$ & .09 & -.08 & -.19 & $.73 * *$ \\
\hline 4. Responsibility & & & & 1.00 & $.52 * *$ & $.34 *$ & $.47 * *$ & .23 & -.16 & .04 & $.74 * *$ \\
\hline 5. Empathy & & & & & 1.00 & $.65^{* *}$ & $.58 * *$ & .18 & -.19 & .04 & $.83 * *$ \\
\hline 6. Engagement & & & & & & 1.00 & $.36^{*}$ & .16 & .10 & $-.27 *$ & $.75 * *$ \\
\hline 7. Self-Control & & & & & & & 1.00 & .12 & -.08 & .34 & $.70 * *$ \\
\hline 8. Risk Cues & & & & & & & & 1.00 & $-.36^{*}$ & -.21 & .20 \\
\hline 9. Latency & & & & & & & & & 1.00 & .07 & -.06 \\
\hline 10. SPAI-Difference & & & & & & & & & & 1.00 & -.02 \\
\hline 11.Social Skills Standard Score & & & & & & & & & & & 1.00 \\
\hline
\end{tabular}

$* * p<.01 ; * p<.05$ 
Table 15.

Correlations between Parent-Rated Social Skills and Risk Perception Using the Total Sample

\begin{tabular}{|c|c|c|c|c|c|c|c|c|c|c|c|}
\hline & 1 & 2 & 3 & 4 & 5 & 6 & 7 & 8 & 9 & 10 & 11 \\
\hline 1. Communication & 1.00 & $.73 * *$ & $.57 * *$ & $.73 * *$ & $.66 * *$ & $.62 * *$ & $.69 * *$ & -.19 & .11 & .07 & $.85^{* *}$ \\
\hline 2. Cooperation & & 1.00 & $.58 * *$ & $.85^{* *}$ & $.82 * *$ & $.65^{* *}$ & $.74 * *$ & -.13 & -.06 & .24 & $.91 * *$ \\
\hline 3. Assertion & & & 1.00 & $.66^{* *}$ & $.54 * *$ & $.64 * *$ & $.43 * *$ & -.08 & .01 & .24 & $.75^{* *}$ \\
\hline 4. Responsibility & & & & 1.00 & $.70 * *$ & $.64 * *$ & $.80 * *$ & -.09 & .07 & $.30^{*}$ & $.90 * *$ \\
\hline 5. Empathy & & & & & 1.00 & $.74^{* *}$ & $.67 * *$ & -.05 & -.07 & .04 & $.87 * *$ \\
\hline 6. Engagement & & & & & & 1.00 & $.61 * *$ & -.20 & .03 & -.10 & $.82 * *$ \\
\hline 7. Self-Control & & & & & & & 1.00 & -.25 & .18 & .13 & $.84^{* *}$ \\
\hline 8. Risk Cues & & & & & & & & 1.00 & $-.36^{*}$ & -.21 & -.18 \\
\hline 9. Latency & & & & & & & & & 1.00 & .07 & .06 \\
\hline 10. SPAI-Difference & & & & & & & & & & 1.00 & .16 \\
\hline 11.Social Skills Standard Score & & & & & & & & & & & 1.00 \\
\hline
\end{tabular}

$* * p<.01 ; * p<.05$ 
Table 16.

Correlations between Student-Rated Social Skills and Risk Perception Using the Target Sample

\begin{tabular}{|c|c|c|c|c|c|c|c|c|c|c|c|}
\hline & 1 & 2 & 3 & 4 & 5 & 6 & 7 & 8 & 9 & 10 & 11 \\
\hline 1.Communication & 1.00 & $.69 * *$ & .36 & $.63 * *$ & .39 & $.44^{*}$ & .22 & -.24 & $.47 *$ & .26 & $.66^{*}$ \\
\hline 2. Cooperation & & 1.00 & .30 & $.81 * *$ & $.54 *$ & $.58 * *$ & $.52 *$ & .16 & -.10 & .00 & $.80 * *$ \\
\hline 3. Assertion & & & 1.00 & .22 & $.64 * *$ & $.82 * *$ & $.70 * *$ & -.07 & .15 & -.20 & $.75 * *$ \\
\hline 4. Responsibility & & & & 1.00 & $.51 *$ & $.55 *$ & $.46^{* *}$ & .21 & .10 & .21 & $.75 * *$ \\
\hline 5. Empathy & & & & & 1.00 & $.78 * *$ & $.56^{* *}$ & .27 & -.11 & -.22 & $.80 * *$ \\
\hline 6. Engagement & & & & & & 1.00 & $.83 *$ & .21 & .28 & .15 & $.92 * *$ \\
\hline 7. Self-Control & & & & & & & 1.00 & .08 & -.02 & -.21 & $.79 * *$ \\
\hline 8. Risk Cues & & & & & & & & 1.00 & $-.62 * *$ & $-.53 *$ & -.12 \\
\hline 9.Latency & & & & & & & & & 1.00 & .21 & .15 \\
\hline 10.SPAI-Difference & & & & & & & & & & 1.00 & -.10 \\
\hline 11.Social Skills Standard Score & & & & & & & & & & & 1.00 \\
\hline
\end{tabular}

$* * p<.01 ; * p<.05$ 
Table 17.

Correlations between Parent-Rated Social Skills and Risk Perception Using the Target Sample

\begin{tabular}{|c|c|c|c|c|c|c|c|c|c|c|c|}
\hline & 1 & 2 & 3 & 4 & 5 & 6 & 7 & 8 & 9 & 10 & 11 \\
\hline 1.Communication & 1.00 & $.74 * *$ & $.51 *$ & $.70 * *$ & $.66^{* *}$ & $.65^{* *}$ & $.61 * *$ & $-.73 * *$ & .21 & $.43 *$ & $.83 * *$ \\
\hline 2. Cooperation & & 1.00 & .39 & $.86^{* *}$ & $.88^{* *}$ & $.66^{* *}$ & $.74^{* *}$ & $-.47^{*}$ & .04 & $.42 *$ & $.90 * *$ \\
\hline 3. Assertion & & & 1.00 & $.55^{*}$ & $.47^{*}$ & $.78 * *$ & .30 & $-.48 *$ & .29 & .37 & $.69 * *$ \\
\hline 4. Responsibility & & & & 1.00 & $.69 * *$ & $.71 * *$ & $.72 * *$ & $-.46^{*}$ & .20 & $.49 *$ & $.89 * *$ \\
\hline 5. Empathy & & & & & 1.00 & $.73^{* *}$ & $.69 * *$ & -.39 & -.02 & .26 & $.88^{* *}$ \\
\hline 6. Engagement & & & & & & 1.00 & $.56^{*}$ & $-.53 *$ & .39 & -.17 & $.87 * *$ \\
\hline 7. Self-Control & & & & & & & 1.00 & $-.54^{*}$ & .33 & $.43^{*}$ & $.79 * *$ \\
\hline 8. Risk Cues & & & & & & & & 1.00 & $-.62 * *$ & $-.53 *$ & $-.63 * *$ \\
\hline 9.Latency & & & & & & & & & 1.00 & .21 & .25 \\
\hline 10.SPAI-Difference & & & & & & & & & & 1.00 & $.44^{*}$ \\
\hline 11.Social Skills Standard Score & & & & & & & & & & & 1.00 \\
\hline
\end{tabular}

$* * p<.01 ; * p<.05$ 
Table 18.

Correlations between Student-Rated Social Skills and Risk Perception Using the Comparison Sample

\begin{tabular}{|c|c|c|c|c|c|c|c|c|c|c|c|}
\hline & 1 & 2 & 3 & 4 & 5 & 6 & 7 & 8 & 9 & 10 & 11 \\
\hline 1.Communication & 1.00 & $.67 * *$ & $.48 * *$ & $.58 * *$ & $.69 * *$ & $.43^{*}$ & $.47 * *$ & .34 & .02 & .11 & $.80 * *$ \\
\hline 2. Cooperation & & 1.00 & $.52 * *$ & $.68 * *$ & $.61 * *$ & $.24 * *$ & $.50 * *$ & .33 & -.22 & .30 & $.80 * *$ \\
\hline 3. Assertion & & & 1.00 & $.37 *$ & $.48 * *$ & $.55 * *$ & $.28 * *$ & .23 & -.25 & -.18 & $.72 * *$ \\
\hline 4. Responsibility & & & & 1.00 & $.52 * *$ & .21 & $.47 * *$ & .25 & -.30 & -.03 & $.73 * *$ \\
\hline 5. Empathy & & & & & 1.00 & $.61 * *$ & $.59 * *$ & .11 & -.17 & .21 & $.87 * *$ \\
\hline 6. Engagement & & & & & & 1.00 & .09 & .12 & .03 & -.31 & $.62 * *$ \\
\hline 7. Self-Control & & & & & & & 1.00 & .14 & -.07 & .16 & $.65 * *$ \\
\hline 8. Risk Cues & & & & & & & & 1.00 & -.18 & -.01 & .28 \\
\hline 9.Latency & & & & & & & & & 1.00 & -.08 & -.19 \\
\hline 10.SPAI-Difference & & & & & & & & & & 1.00 & .04 \\
\hline 11.Social Skills Standard Score & & & & & & & & & & & 1.00 \\
\hline
\end{tabular}

$* * p<.01 ; * p<.05$ 
Table 19.

Correlations between Parent-Rated Social Skills and Risk Perception Using the Comparison Sample

\begin{tabular}{|c|c|c|c|c|c|c|c|c|c|c|c|}
\hline & 1 & 2 & 3 & 4 & 5 & 6 & 7 & 8 & 9 & 10 & 11 \\
\hline 1. Communication & 1.00 & $.73 * *$ & $.64 * *$ & $.76^{* *}$ & $.68 * *$ & $.61^{* *}$ & $.76^{* *}$ & .24 & .00 & -.14 & $.86 * *$ \\
\hline 2. Cooperation & & 1.00 & $.78 * *$ & $.84 * *$ & $.77 * *$ & $.64^{* *}$ & $.76^{* *}$ & -.16 & .15 & .14 & $.92 * *$ \\
\hline 3. Assertion & & & 1.00 & $.79 * *$ & $.62 * *$ & $.52 * *$ & $.59 * *$ & $.37^{*}$ & -.23 & .16 & $.81 * *$ \\
\hline 4. Responsibility & & & & 1.00 & $.72 * *$ & $.59 * *$ & $.87 * *$ & .25 & -.08 & .17 & $.92 * *$ \\
\hline 5. Empathy & & & & & 1.00 & $.75^{* *}$ & $.67 * *$ & .27 & -.09 & -.09 & $.86^{* *}$ \\
\hline 6. Engagement & & & & & & 1.00 & $.67 * *$ & .09 & -.22 & -.24 & $.79 * *$ \\
\hline 7. Self-Control & & & & & & & 1.00 & .03 & .01 & -.10 & $.88 * *$ \\
\hline 8. Risk Cues & & & & & & & & 1.00 & -.18 & -.01 & .23 \\
\hline 9. Latency & & & & & & & & & 1.00 & -.01 & -.12 \\
\hline 10.SPAI-Difference & & & & & & & & & & 1.00 & -.02 \\
\hline 11.Social Skills Standard Score & & & & & & & & & & & 1.00 \\
\hline
\end{tabular}

$* * p<.01 ; * p<.05$ 
Table 20.

Correlations among Mental Health Symptoms and Sexual Abuse

\begin{tabular}{|c|c|c|c|c|c|c|c|c|c|c|c|c|}
\hline & 1 & 2 & 3 & 4 & 5 & 6 & 7 & 8 & 9 & 10 & 11 & 12 \\
\hline 1. BDI-II & 1.00 & $.37 * *$ & -.12 & $.28 *$ & -.16 & $.61 * *$ & -.19 & -.22 & $-.43 * *$ & $-.42 * *$ & -.18 & $-.38 * *$ \\
\hline 2. MASC Physical & & 1.00 & -.09 & $.41 * *$ & .19 & $.48^{* *}$ & .01 & -.04 & -.09 & -.11 & -.07 & -.23 \\
\hline 3. MASC Harm Avoidance & & & 1.00 & -.14 & .09 & -.14 & .16 & .06 & .26 & .19 & .24 & $.28^{*}$ \\
\hline 4. MASC Social Anxiety & & & & 1.00 & $.33^{*}$ & .10 & .18 & .21 & .08 & .07 & .14 & -.16 \\
\hline 5. SPAI Difference & & & & & 1.00 & -.11 & .07 & .24 & .24 & $.29 *$ & .04 & -.10 \\
\hline 6. CPSS & & & & & & 1.00 & -.14 & $-.27^{*}$ & -.27 & $-.39 * *$ & $-.29 *$ & -.26 \\
\hline 7. SSIS-P communication & & & & & & & 1.00 & $.73 * *$ & $.57 * *$ & $.73 * *$ & $.66^{* *}$ & $.62 * *$ \\
\hline 8. SSIS-P Cooperation & & & & & & & & 1.00 & $.58 * *$ & $.85^{* *}$ & $.82 * *$ & $.65 * *$ \\
\hline 9. SSIS-P Assertion & & & & & & & & & 1.00 & $.66^{* *}$ & $.54 * *$ & $.64 * *$ \\
\hline 10.SSIS-P Responsibility & & & & & & & & & & 1.00 & $.70 * *$ & $.64 * *$ \\
\hline 11.SSIS-P Empathy & & & & & & & & & & & 1.00 & $.74 * *$ \\
\hline 12.SSIS-P Engagement & & & & & & & & & & & & 1.00 \\
\hline
\end{tabular}


Table 20 (continued).

\begin{tabular}{|c|c|c|c|c|c|c|c|c|c|c|c|c|c|}
\hline & 12 & 13 & 14 & 15 & 16 & 17 & 18 & 19 & 20 & 21 & 22 & 23 & 24 \\
\hline 1. BDI-II & $-.38 * *$ & $-.29 *$ & $-.26^{*}$ & $-.34^{*}$ & -.17 & -.29 & -.08 & -.11 & -.27 & .09 & .15 & $-.29 *$ & $-.35^{*}$ \\
\hline 2. MASC Physical Symptoms & -.21 & -.19 & -.25 & -.14 & -.01 & $-.41 * *$ & -.15 & -.05 & -.18 & .16 & -.15 & -.21 & -.13 \\
\hline 3. MASC Harm Avoidance & .23 & .08 & .24 & .26 & $.41 * *$ & $.34 *$ & .14 & .09 & .24 & $.34^{*}$ & .01 & $.32 *$ & .19 \\
\hline 4. MASC Social Anxiety & -.19 & -.10 & -.23 & -.18 & $-.40 * *$ & -.19 & -.22 & $-.50 * *$ & -.08 & -.22 & .03 & $-.36^{*}$ & .04 \\
\hline 5. SPAI Difference & -.10 & .13 & .15 & .18 & -.19 & .04 & .04 & $-.27 *$ & .04 & $-.38 * *$ & -.16 & -.02 & .16 \\
\hline 6. CPSS & -.26 & $-.29 *$ & -.04 & -.03 & .10 & -.18 & .05 & .14 & -.17 & $.32 *$ & .04 & -.02 & $-.32 *$ \\
\hline 7. SSIS-P communication & $.62 * *$ & $.69^{* *}$ & .13 & .08 & -.01 & $.31 *$ & -.03 & .01 & .09 & .01 & -.09 & .11 & $.85 * *$ \\
\hline 8. SSIS-P Cooperation & $.65 * *$ & $.74 * *$ & -.04 & .05 & -.15 & $.30 *$ & -.03 & -.15 & .18 & -.08 & .02 & .03 & $.91 * *$ \\
\hline 9. SSIS-P Assertion & $.64 * *$ & $.43^{* *}$ & .16 & .22 & $.28^{*}$ & $.35^{*}$ & .09 & .13 & .31 & .07 & .01 & $.29^{*}$ & $.75^{* *}$ \\
\hline 10.SSIS-P Responsibility & $.64 * *$ & $.80 * *$ & .17 & .18 & -.03 & $.41 * *$ & -.02 & -.05 & .21 & -.11 & -.09 & .16 & $.90 * *$ \\
\hline 11.SSIS-P Empathy & $.74 * *$ & $.67 * *$ & -.03 & -.04 & .09 & .26 & .15 & .13 & $.29 *$ & .11 & .03 & .17 & $.87 * *$ \\
\hline 12.SSIS-P Engagement & 1.00 & $.61 * *$ & .10 & .08 & .24 & $.29 *$ & .15 & .24 & .12 & .17 & .01 & .24 & $.82 * *$ \\
\hline
\end{tabular}


Table 20 (continued).

\begin{tabular}{|c|c|c|c|c|c|c|c|c|c|c|c|c|}
\hline & 1 & & 3 & 4 & 5 & 6 & 7 & 8 & 9 & 10 & 11 & 12 \\
\hline 12.SSIS-P Engagement & $-.38 * *$ & -.24 & $.28 *$ & -.16 & -.10 & -.26 & $.62 * *$ & $.65 * *$ & $.64 * *$ & $.64 * *$ & $.74 * *$ & 1.00 \\
\hline 13.SSIS-P Self-Control & $-.29 *$ & -.14 & .15 & -.03 & .13 & $-.29 *$ & $.69 * *$ & $.74 * *$ & $.43 * *$ & $.80 * *$ & $.67 * *$ & $.61 * *$ \\
\hline 14.SSIS-S Communication & $-.26^{*}$ & -.16 & $.29 *$ & -.18 & .15 & -.04 & .13 & -.04 & .16 & .17 & -.03 & .10 \\
\hline 15.SSIS-S Cooperation & $-.34 *$ & -.07 & .18 & -.12 & .18 & -.03 & .08 & .05 & .22 & .18 & -.04 & .08 \\
\hline 16.SSIS-S Assertion & -.17 & -.07 & $.41 * *$ & $-.40 * *$ & -.19 & .10 & -.01 & -.15 & $.28 *$ & -.03 & .09 & .24 \\
\hline 17.SSIS-S Responsibility & -.29 & $-.36 *$ & $.34^{*}$ & -.14 & .04 & -.18 & $.32 *$ & $.30 *$ & $.35^{*}$ & $.41 * *$ & .26 & $.29 *$ \\
\hline 18.SSIS-S Empathy & -.08 & -.20 & .23 & -.17 & .04 & .05 & -.03 & -.03 & .09 & -.02 & .15 & .15 \\
\hline 19.SSIS-S Engagement & -.11 & -.10 & .18 & $-.47 * *$ & $-.27 *$ & .14 & .01 & -.14 & .13 & -.05 & .13 & .24 \\
\hline 20.SSIS-S Self-Control & $-.27 *$ & -.16 & .28 & -.03 & .04 & -.17 & .09 & .18 & $.31 *$ & .21 & $.29 *$ & .12 \\
\hline 21. Severity Score & .09 & .09 & .23 & -.22 & $-.38 * *$ & $.32 *$ & .01 & -.08 & .07 & -.11 & .11 & .17 \\
\hline 22.Group Membership & .15 & -.16 & -.11 & .08 & -.16 & .04 & -.09 & -.02 & .01 & -.09 & .03 & .01 \\
\hline 23.Social Skills Std Score-S & $-.29 *$ & -.21 & $.36^{*}$ & $-.30 *$ & -.02 & -.02 & .11 & .03 & $.29 *$ & .16 & .17 & .24 \\
\hline 24.Social Skills Std Score-P & $-.36^{*}$ & -.10 & .23 & .09 & .16 & $-.32 *$ & $.85^{* *}$ & $.91 * *$ & $.75 * *$ & $.90 * *$ & $.87 * *$ & $.82 * *$ \\
\hline
\end{tabular}


Table 20 (continued).

\begin{tabular}{|c|c|c|c|c|c|c|c|c|c|c|c|c|c|}
\hline & 12 & 13 & 14 & 15 & 16 & 17 & 18 & 19 & 20 & 21 & 22 & 23 & 24 \\
\hline 12. SSIS-P Engagement & 1.00 & $.61 * *$ & .10 & .08 & .24 & $.29 *$ & .15 & .24 & .12 & .17 & .01 & .24 & $.82 * *$ \\
\hline 13. SSIS-P Self-Control & & 1.00 & .24 & .24 & .04 & $.44 * *$ & .06 & .05 & .26 & -.14 & -.14 & .24 & $.84 * *$ \\
\hline 14. SSIS-S Communication & & & 1.00 & $.67 * *$ & $.42 * *$ & $.60 * *$ & $.58 * *$ & $.42 * *$ & $.38 * *$ & .01 & .07 & $.74 * *$ & .12 \\
\hline 15. SSIS-S Cooperation & & & & 1.00 & $.42 * *$ & $.73 * *$ & $.56^{* *}$ & $.40 * *$ & $.49 * *$ & .20 & -.02 & $.80^{* *}$ & .13 \\
\hline 16. SSIS-S Assertion & & & & & 1.00 & $.30^{*}$ & $.54 * *$ & $.68 * *$ & $.43 * *$ & $.38 * *$ & .02 & $.73 * *$ & .08 \\
\hline 17. SSIS-S Responsibility & & & & & & 1.00 & $.52 * *$ & $.34^{*}$ & $.47 * *$ & .15 & .09 & $.74 * *$ & $.39 * *$ \\
\hline 18. SSIS-S Empathy & & & & & & & 1.00 & $.65^{* *}$ & $.58 * *$ & .12 & .16 & $.83 * *$ & .05 \\
\hline 19. SSIS-S Engagement & & & & & & & & 1.00 & $.36^{*}$ & $.31 *$ & -.09 & $.75 * *$ & .05 \\
\hline 20. SSIS-S Self-Control & & & & & & & & & 1.00 & .19 & .07 & $.70 * *$ & .24 \\
\hline 21. Severity Score & & & & & & & & & & 1.00 & $.36^{* *}$ & $.27 *$ & .00 \\
\hline 22. Group Membership & & & & & & & & & & & 1.00 & .05 & -.06 \\
\hline 23. Social Skills Std Score-S & & & & & & & & & & & & 1.00 & .20 \\
\hline 24. Social Skills Std Score-P & & & & & & & & & & & & & 1.00 \\
\hline
\end{tabular}

$* * p<.01 ; * p<.05$ 
Table 21.

Correlations between Reports of Coping Styles in the Total Sample

\begin{tabular}{|c|c|c|c|c|c|c|c|c|c|c|}
\hline & 1 & 2 & 3 & 4 & 5 & 6 & 7 & 8 & 9 & 10 \\
\hline 1. Vignette Approach/Expressive & 1.00 & -.26 & -.13 & .17 & -.09 & .25 & .20 & .17 & .04 & $.30^{*}$ \\
\hline 2. Vignette Avoidant & & 1.00 & .16 & $-.28 *$ & -.04 & -.08 & -.24 & -.06 & .01 & $-.35^{*}$ \\
\hline 3. Vignette Nervous/Anxious & & & 1.00 & -.14 & $.38 * *$ & .20 & -.08 & -.02 & .19 & .16 \\
\hline 4. Vignette/Cognitive & & & & 1.00 & -.15 & .10 & .06 & .18 & -.08 & -.07 \\
\hline 5. Vignette Self-Destructive & & & & & 1.00 & -.04 & .23 & .01 & $.41 * *$ & -.12 \\
\hline 6. HIDT Cognitive & & & & & & 1.00 & $.40 * *$ & $.63 * *$ & $.33 *$ & $.54 * *$ \\
\hline 7. HIDT Nervous/Anxious & & & & & & & 1.00 & $.49 * *$ & $.44 * *$ & $.44 * *$ \\
\hline 8. HIDT Avoidance & & & & & & & & 1.00 & $.28 *$ & $.40 * *$ \\
\hline 9. HIDT Self-Destructive & & & & & & & & & 1.00 & .01 \\
\hline 10.HIDT Expressive & & & & & & & & & & 1.00 \\
\hline
\end{tabular}

$* * p<.01 ; * p<.05$ 
Table 22.

Correlations between Reports of Coping Styles in the Target Sample

\begin{tabular}{|c|c|c|c|c|c|c|c|c|c|c|}
\hline & 1 & 2 & 3 & 4 & 5 & 6 & 7 & 8 & 9 & 10 \\
\hline 1. Vignette Approach/Expressive & 1.00 & .03 & -.22 & .18 & -.21 & .15 & .26 & .09 & -.20 & .22 \\
\hline 2. Vignette Avoidant & & 1.00 & -.16 & -.17 & .04 & -.06 & -.10 & .03 & .03 & $-.44^{*}$ \\
\hline 3. Vignette Nervous/Anxious & & & 1.00 & -.14 & $.63 * *$ & -.03 & .00 & -.16 & $.56^{* *}$ & .28 \\
\hline 4. Vignette/Cognitive & & & & 1.00 & -.29 & .01 & -.11 & .03 & -.08 & -.21 \\
\hline 5. Vignette Self-Destructive & & & & & 1.00 & -.02 & .26 & -.04 & $.63 * *$ & -.15 \\
\hline 6. HIDT Cognitive & & & & & & 1.00 & $.62 * *$ & $.55^{*}$ & .29 & .40 \\
\hline 7. HIDT Nervous/Anxious & & & & & & & 1.00 & $.72 * *$ & .38 & $.48^{*}$ \\
\hline 8. HIDT Avoidance & & & & & & & & 1.00 & .30 & .38 \\
\hline 9. HIDT Self-Destructive & & & & & & & & & 1.00 & .01 \\
\hline 10.HIDT Expressive & & & & & & & & & & 1.00 \\
\hline
\end{tabular}

$* * p<.01 ; * p<.05$ 
Table 23.

Correlations between Reports of Coping Styles in the Comparison Sample

\begin{tabular}{|c|c|c|c|c|c|c|c|c|c|c|}
\hline & 1 & 2 & 3 & 4 & 5 & 6 & 7 & 8 & 9 & 10 \\
\hline 1. Vignette Approach/Expressive & 1.00 & .34 & -.07 & .16 & -- & .30 & .15 & .22 & .17 & $.38^{*}$ \\
\hline 2. Vignette Avoidant & & 1.00 & .30 & $-.36^{*}$ & -- & -.12 & -.27 & -.07 & .01 & $-.35^{*}$ \\
\hline 3. Vignette Nervous/Anxious & & & 1.00 & -.14 & -- & .30 & -.13 & .13 & -.08 & .06 \\
\hline 4. Vignette/Cognitive & & & & 1.00 & -- & .29 & .14 & .34 & -.11 & .18 \\
\hline 5. Vignette Self-Destructive & & & & & -- & -- & -- & -- & -- & -- \\
\hline 6. HIDT Cognitive & & & & & & 1.00 & $.38^{*}$ & $.82 * *$ & $.37 *$ & $.64 * *$ \\
\hline 7. HIDT Nervous/Anxious & & & & & & & 1.00 & .20 & $.50 * *$ & $.46^{*}$ \\
\hline 8. HIDT Avoidance & & & & & & & & 1.00 & .28 & $.46^{*}$ \\
\hline 9. HIDT Self-Destructive & & & & & & & & & 1.00 & .01 \\
\hline 10.HIDT Expressive & & & & & & & & & & 1.00 \\
\hline
\end{tabular}

$* * p<.01 ; * p<.05 ;--$ constant variable (not endorsed) 